\title{
Using mathematics to avoid blindness in diabetics
}

Arieh Helfgott ${ }^{1,2}$, Ariella ER Helfgott ${ }^{3,4}$, Sean Mullany $y^{5,6}$

${ }^{1}$ The Australian Mathematical Society, Canberra, Australia; ${ }^{2}$ The Cardiac Society of Australia and New Zealand, Sydney, Australia; ${ }^{3}$ Copernicus Institute of Sustainable Development, Utrecht University, Utrecht, The Netherlands; ${ }^{4}$ Environmental Change Institute, University of Oxford, Oxford, UK; ${ }^{5}$ The Royal Adelaide Hospital, Adelaide, Australia; ${ }^{6}$ Department of Medicine, Flinders University, Adelaide, Australia

\section{Abstract}

Purpose: Avoid diabetic-blindness by applying five simple mathematically-inspired treatments that achieve life-long recovery from advanced diabetic retinopathy (ADR), without laser treatments or Avastin (Hoffmann-La Roche, Basel, Switzerland) injections.

Methods: A mathematical model of ADR is derived; it is based on fluid leakage from abnormal 'holes' in small retinal blood vessels. First, the volume of a microscopic fluid droplet leaking from a single small vein-hole during a single heartbeat is derived from the Navier-Stokes flow-equations. Then, total fluid volume leaking into the retina from all $\mathrm{M}$ vein holes in $\mathrm{N}$ heartbeats is determined. Six parameters in the equations of the model with significant influence on leakage rates and leaked volumes are identified. These insights are used to design and then apply five simple, novel, and efficient therapeutic treatments, T1 to T5, that may achieve recovery from ADR without laser surgery or Avastin injections. Daily rates, as well as total volumes, of macular fluid accumulation, removal (by eye-pumps), and leakage are calculated from optical coherence tomography (OCT)-measured macular thicknesses.

Results: Ten years ago, this paper's primary author, Arieh Helfgott (AH), suffered from ADR that no longer responded to laser surgery. After simultaneous application of treatments T1-T5, AH recovered from ADR in 42 days and has been free of ADR for over ten years, without needing Avastin injections. Leakage-volumes were shown to be very sensitive to small changes in hole diameters. In ADR, modest increases of $2.4 \%, 5.7 \%, 10.7 \%, 15 \%$, and $19 \%$ in hole diameters induce impressive $10 \%, 25 \%$,

Correspondence: Dr. Arieh Helfgott E-mail: ariehhelfgott@bigpond.com 
$50 \%, 75 \%$, and $100 \%$ (volume-doubling) increases in leakage volumes, respectively. In recovery from $A D R$, modest decreases of $-2.6 \%,-5.4 \%,-8.5 \%,-12 \%$, and $-15.9 \%$ in hole diameters induce equally impressive $-10 \%,-20 \%,-30 \%,-40 \%$, and $-50 \%$ (volume-halving) decreases in leakage volumes, respectively.

Conclusion: In AH's case, mathematics helped in avoiding blindness from ADR. Simultaneous application of mathematics-inspired treatments T1-T5 resulted in reduced leakage from holes, elimination of retinal swelling (RS), and sustained recovery from ADR. With high sensitivity to hole diameters, advancing DR can easily become unmanageable, while recovery from ADR may possibly be achievable in approximately six weeks using efficient blood pressure (BP) control and small 'repairs' leading to reduction in hole diameters. The pumping rate of the eye is colossal; eye pumps can remove a macula-volume-equivalent in approximately 44 days. This is very helpful in recovery from ADR, and spectacular for such microscopic pumps.

Keywords: advanced diabetic retinopathy (ADR) treatment, blindness, blood flow, diabetic retinopathy (DR), diabetes, leaking blood vessels, macula, mathematical model, retina

\section{Introduction}

\subsection{Diabetic retinopathy (DR)}

DR is a serious sight-threatening complication of diabetes. In 2013, the Australian Baker Institute reported that DR is a leading cause of irreversible blindness in Australian adults, and the leading cause of blindness in working age adults in the world. ${ }^{1}$ More recent epidemiological studies confirm that DR is a leading cause of vision loss and blindness globally (e.g., 2015 review by Lee at al.). ${ }^{2}$ As rates of diabetes rise in both developed and developing countries, and as ageing and life expectancy of the population with diabetes increase, vision impairment and blindness caused by diabetic eye disease is an issue of growing global significance. ${ }^{2}$

The excellent texts by Gloria $\mathrm{Wu}^{3}$ and Jon Walker describe the basic data on DR, its epidemiology, pathogenesis, and current guidelines for treatment. Over time, diabetes gradually damages tiny blood vessels in the microcirculation of the retina (arterioles, capillaries, venules, etc). This damage can eventually lead to formation of abnormal 'holes' in retinal blood vessel walls. ${ }^{3,4}$ DR occurs when the vessels leak blood and fluids from the holes into the retina, which causes retinal tissue to swell (retinal edema). The result is cloudy or blurred vision. DR usually affects both eyes. The longer a person has diabetes, the more likely they will develop DR. ${ }^{3,4,5}$ If left untreated, DR can cause blindness.

In advancing DR, retinal blood vessels eventually become so abnormal and full of leaking holes (Table 15.9 in $\mathrm{Wu}$ ), ${ }^{3}$ that they lose significant functionality. In an attempt to improve retinal blood circulation, new blood vessels begin to grow 
in the retina and into the vitreous. This proliferative retinal neo-vascularization is the more advanced form of DR. The new blood vessels are abnormal; they are very thin-walled, fragile, and 'leakier' than ordinary retinal vessels, and so they may leak blood into the back of the eye, blocking vision. ${ }^{3,4}$

Even though there is no cure for DR, there are available treatments; ${ }^{3}$ laser treatment (photocoagulation) is usually very effective at preventing vision loss if it is done before the retina has been severely damaged. Sometimes, injections of an anti-vascular endothelial growth factor (VEGF) drug, such as Avastin, help in shrinking new blood vessels in proliferative DR. In general, the earlier DR is detected, the easier it is to treat and the more likely vision will be preserved. Also, controlling blood sugar levels is always important, even after successful treatments for DR, since this will keep DR from getting worse.

Retinal thickness at various retinal locations is a good quantifier of RS. It is measured in microns ( 1 micron $=1$ millionth of a meter). In normal eyes, average foveal thickness at the center of the macula is about 200 microns or less. ${ }^{6}$ In ADR, foveal thickness can increase further and further and, if not treated, can reach about 800 microns (Fig. 1 in Browning) ${ }^{7}$ at which point the patient is considered clinically blind. The status of current clinical thinking on DR can be summarized as follows:3,4

1. DR is a complication of diabetes that affects the eyes. Vision loss or blindness can occur.

2. DR is caused by damage to blood vessels in retinal tissue at the back of the eye.

3. Treatment can help, but this condition cannot be cured.

4. DR requires a medical diagnosis.

5. Laboratory tests or imaging are always required.

6. DR is chronic: it can last for years or be life-long.

7. Poorly controlled blood sugar level is a significant risk factor.

8. Early symptoms include floaters, blurriness, dark areas of vision, and difficulty perceiving colors.

9. Mild cases of DR may be treated with careful diabetes management.

10. Advanced DR cases may require laser treatment, surgery, or injections of an anti-VEGF drug such as Avastin.

This paper presents an alternative perspective, namely, that ADR cases may perhaps also be successfully treated with simultaneous application of five other measures, T1 to T5, described in the Methods section below.

\subsection{Some basic retina details for mathematicians and engineers}

The retina is the light-sensitive lining at the back of the eye. The macula is a small but vital area of the retina, about $5.5 \mathrm{~mm}$ in diameter, and is the part of the retina that is the most densely packed with seeing cells. The macula produces clear central (focused) vision, allowing us to see fine detail and colors. The rest of the retina is for side (peripheral) vision. 
Blood vessels at the back of the eye nourish the retina. The inner layers of the retina get their blood supply from retinal arteries and veins, which run within the retina itself. The arteries help carry oxygen and nutrients to the retina, and veins drain blood away from the retina and back towards the heart. The fovea is a tiny pit at the very center of the macula that provides the clearest vision of all. Only in the fovea are the layers of the retina spread aside to let light fall directly on the cones, the cells that provide the sharpest image. It is also called the central fovea (fovea centralis).

\subsection{Retinal and macular thickness and volume}

OCT is commonly used to reliably measure macular thickness and volume. In the north China Handan Eye Study, ${ }^{8}$ macular thickness in 2230 eyes of healthy normal subjects was measured with Zeiss Stratus OCT Model 3000 scans. Scans were performed over maculae within a diameter $D_{m}=6 \mathrm{~mm}$, divided into three regions (central, inner, and outer, with a diameter of 1, 3, and $6 \mathrm{~mm}$, respectively), and nine quadrants (one in the central region, and four each in the inner and outer regions). The study ${ }^{8}$ found mean total macular volume in normal subjects to be $V_{m \infty}=6.76 \mathrm{~mm}^{3}$. The macular surface area contained within diameter $D_{m}=6 \mathrm{~mm}$ is $S_{m}=28.274 \mathrm{~mm}^{2}$ $(\pi \times 9)$. Hence, mean total macular thickness in normal subjects is $H_{m \infty}=0.239 \mathrm{~mm}=$ 239 microns $\left(6.76 \mathrm{~mm}^{3} / 28.274 \mathrm{~mm}^{2}\right)$. Here the infinity symbol, $\infty$, stands for time-unchanging thickness or volume, and $m$ for macula. In studies of different ethnic groups, ${ }^{8}$ measured $V_{m \infty}$ was: $6.486 \mathrm{~mm}^{3}$ (India); $6.660 \mathrm{~mm}^{3}$ (USA); $7.100 \mathrm{~mm}^{3}$ (China); and 6.780 (UK). The mean of the four ethnic groups was again $V_{m \infty}=6.76 \mathrm{~mm}^{3}$; hence, this value was used in this paper.

The older Zeiss Stratus is a time-domain device (TD-OCT), whereas most new devices, like the Zeiss Cirrus or Heidelberg Spectralis, are spectral-domain (SD-OCT) devices. The new SD-OCT devices can acquire much more information in much less time, providing more accurate measurements of thickness and volume. ${ }^{4}$ However, different new OCT devices can produce noticeably different results, a comparison of which is beyond the scope of this paper.

The above mean macular thickness and volume were obtained with 'old' TD-OCT machines, available more than ten years ago. The macular OCT scans of this paper's primary author $(\mathrm{AH})$, which form the basis of calculations in the Methods section, were also obtained more than ten years ago with an old TD-OCT machine. For compatibility reasons, it was therefore appropriate to use $V_{m \infty}=6.76 \mathrm{~mm}^{3}$ in this paper. The average surface area of the whole retina, $\mathrm{S}$, is now a known parameter. Most recently (2017), using magnetic resonance imaging, Nagra ${ }^{9}$ reported an average S of $1363 \mathrm{~mm}^{2}$. OCT scans for diameters greater than $D_{\mathrm{m}}=6 \mathrm{~mm}$ are currently not available in the clinical setting. 


\subsection{Proposed mechanism of fluid leakage from abnormal holes in retinal blood vessels}

In what follows, blood vessels of the retinal microcirculation (arterioles, pre-capillaries, capillaries, venules, etc.) are collectively referred to as 'small veins' or just 'veins', and all pressures are defined relative to the atmospheric pressure.

Pressure within small veins is pulsatile, showing periodic fluctuations that can be quite considerable. ${ }^{10}$ In normal cats, the pressure consists of a virtually constant pressure, upon which small cardiac oscillations are superimposed. Normal amplitude of oscillations is approximately $1-2 \mathrm{mmHg}(2-4 \mathrm{mmHg}$ total pressure variation), but amplitude could increase to about twice this level, i.e., 2-4 mmHg (4-8 $\mathrm{mmHg}$ total pressure variation), if the precapillary sphincter became dilated (p. 371 and Fig. 13.19 in Caro et al.)..$^{10}$ In hypertensive cats, amplitude of oscillations can be approximately $1 \mathrm{mmHg}$ greater than in normo-tensive cats (estimated from Figs. 13.16 and 13.18 in Caro et al.). ${ }^{10}$ Hence, in hypertensive cats, amplitude of oscillations can be approximately 3-5 $\mathrm{mmHg}$, and so periodic cardiac pressure fluctuations inside small veins can be approximately $6-10 \mathrm{mmHg}$.

Information gained from the cat studies provides a clear idea of temporal cardiac pressure variations inside small veins. Cats (felines) are commonly and successfully used in cardiovascular research due to their similarity in anatomical basis and physiological functions with humans. Accordingly, in this study it was assumed that the above cat information also applies to human subjects and, in particular, to hypertensive diabetic human subjects. That is, it was assumed that in ADR, periodic cardiac pressure fluctuations can be of the order of 6-10 $\mathrm{mmHg}$, due to increased pulsatile pressure in larger central arteries (aorta, etc.).

Let:

1. $P_{1}(t)=P_{\text {VEIN }}(t)=$ Transient pulsatile pressure inside small retinal veins, at the inlet to abnormal holes in their walls (intravascular pressure); and

2. $P_{2}(t)=P_{R E T}(t)=$ Pressure in the interstitial retinal space outside abnormal holes (extravascular pressure).

Extravascular pressure $P_{R E T}(t)$ in retinal tissue surrounding leaking veins can vary with time, but is normally fairly constant and slightly sub-atmospheric (p. 376-377 in Caro et al.)..$^{10}$ But intravascular pressure $\mathrm{P}_{\mathrm{VEIN}}(\mathrm{t})$ inside small veins varies during the cardiac cycle, being low during diastole and higher during systole. In normotensive subjects, temporal cardiac pressure variations are small, but in hypertensive human subjects with ADR they can be much larger $(6-10 \mathrm{mmHg})$.

Transmural pressure (TP) drop, $\mathrm{P}_{\text {VEIN }}(\mathrm{t})-\mathrm{P}_{\mathrm{RET}}(\mathrm{t})$, provides the driving force for fluid leakage from abnormal holes into the retina. Since $P_{R E T}(t)$ is almost constant, TP fluctuations are primarily determined by fluctuations in pressure $P_{\text {VEIN }}(t)$, the major contributor to TP drop. Because venous pressures $P_{\text {VEIN }}(t)$ in micro-vessels are generally very low, they were traditionally, and understandably, considered clinically unimportant and were ignored (AH experienced this personally). In ADR, $\mathrm{P}_{\mathrm{VEIN}}(\mathrm{t})$ drives leakage flow from vein holes, and therefore, it should never be ignored. 


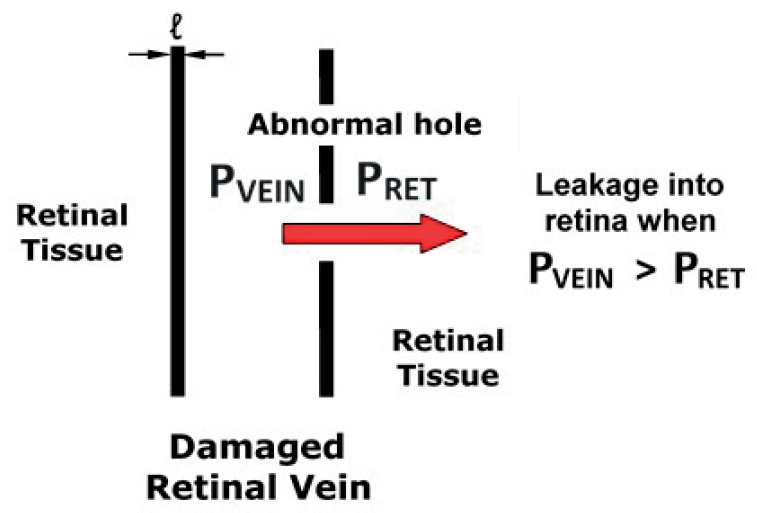

Fig. 1. Diagram illustrating fluid leaking from a tiny abnormal hole in a vein's wall into surrounding retinal tissue. This happens when PVEIN > PRET, that is, when pressure inside the vein exceeds pressure in the surrounding tissue just outside the vein. $l=$ blood vessel wall-thickness $=$ abnormal hole length .

Figure 1 graphically illustrates fluid leaking from an abnormal vein-hole into surrounding retinal tissue when pressure $P_{\text {VEIN }}>P_{\text {RET }}$ (inside pressure exceeds outside pressure). The positive TP difference forces fluid to leak sideways into the retina through the hole's exit cross-section. Figure 2 diagrammatically illustrates temporal pressure $\mathrm{P}_{\text {VEIN }}(\mathrm{t})$ variations inside a small vein during a single cardiac cycle. Pressure rises from low diastolic levels to higher systolic levels, then drops back again to low diastolic levels. Leakage occurs when $P_{\text {VEIN }}>P_{R E T}$, but does not occur when $P_{\text {VEIN }} \leq P_{\text {RET }}$, i.e., when inside pressure is below outside pressure. Fluid leakage starts the moment $P_{\text {VEIN }}$ rises above $P_{R E T}$, and continues until eventually $P_{\text {VEIN }}$ drops below $\mathrm{P}_{\mathrm{RET}}$, at which point leakage stops (colored peaks in Fig. 2). The longer leaking lasts, the larger the volume of fluid leaking into the retina will be. For hypertensive subjects ('High vein BP' curve in Fig. 2), the gold-colored peak area is significantly larger than the green-colored peak area of normotensive subjects ('Normal vein BP 'curve' in Fig. 2). An important observation can now be made:

In hypertensive diabetic subjects suffering from $A D R$, each heartbeat contributes to fluid accumulation in retinal tissues, and so with each successive heartbeat, a diabetic subject gets closer and closer to blindness! This is an unusual and unique medical condition in which one's heartbeats act against one's interests.

Fortunately, the eye has many pumps capable of removing fluids from the retina. Let $Q_{\text {PUMP }}$ and $Q_{\text {LEAK }}$ denote fluid removal rate by pumps and fluid leakage rate from holes in veins, respectively. In normotensive subjects, $Q_{\text {PUMP }}>Q_{\text {LEAK }}$, and the pumps can easily remove excess fluids from the retina because $Q_{\text {PuMP }}$ is larger than the normally low $\mathrm{Q}_{\text {LEAK }}$ of normal subjects. This is, however, not the case for hypertensive diabetic subjects. In hypertension, $\mathrm{Q}_{\text {PUMP }}<\mathrm{Q}_{\text {LEAK }}$, and the pumps can no longer cope with the abnormally large leakage rates, thus leading to unwanted RS. 


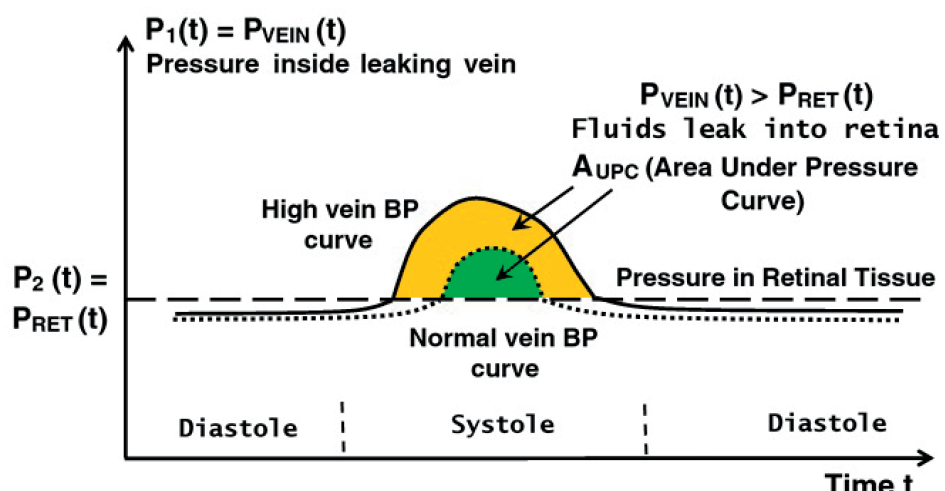

Fig. 2. Diagram showing temporal pressure $\mathrm{P}_{\text {VEIN }}(t)$ variations inside a damaged small retinal vein during a single cardiac cycle. Pressure rises from low diastolic levels to higher systolic levels, then drops again to low diastolic levels. Fluid starts leaking when $\mathrm{P}_{\text {VEIN }}$ rises above $\mathrm{P}_{\text {RET }}$ (pressure in retinal tissue outside vein), and continues leaking until $P_{\text {VEIN }}$ drops below $P_{\text {RET }}$ (see colored peaks). The longer leaking lasts, the larger the amount of fluid leaking into retinal tissues will be. For hypertensive subjects ('High vein BP' curve), the area of the gold-colored peak is significantly larger than the area of the green-colored peak of normotensive subjects ('Normal vein BP' curve).

In AH's ADR, this problem was overcome with five effective treatments that reduced (not eliminated!) the rate of fluid leakage from veins, thus restoring the ability of the pumps to cope again with leakages from veins (described below).

\section{Methods}

In this section, a mathematical model of advanced DR is derived; it is based on flow equations describing fluid leakage from abnormal holes in small veins. First, the volume of a fluid droplet leaking into the retina from a single microscopic hole in a single heartbeat is determined. Then, the total volume of fluid leaking into the retina from $\mathrm{M}$ holes in $\mathrm{N}$ heartbeats is calculated by summing up individual droplet volumes over $\mathrm{M}$ holes and $\mathrm{N}$ heartbeats.

Mathematical description of pulsatile flow through a vein's hole requires analysis of unsteady (transient) flows in very short tubes. Since there are no fluid mechanics texts that analyze this type of a flow (not even Batchelor's mathematically advanced fluid dynamics book), ${ }^{11}$ leakage flow equations were derived from the fundamental continuity and Navier-Stokes equations, after establishing first upper bounds for Reynolds numbers, Womersley numbers, and entrance lengths in abnormal holes 'created' by DR or ADR.

The model is based on the assumption that fluid filtration out of blood micro-ves- 


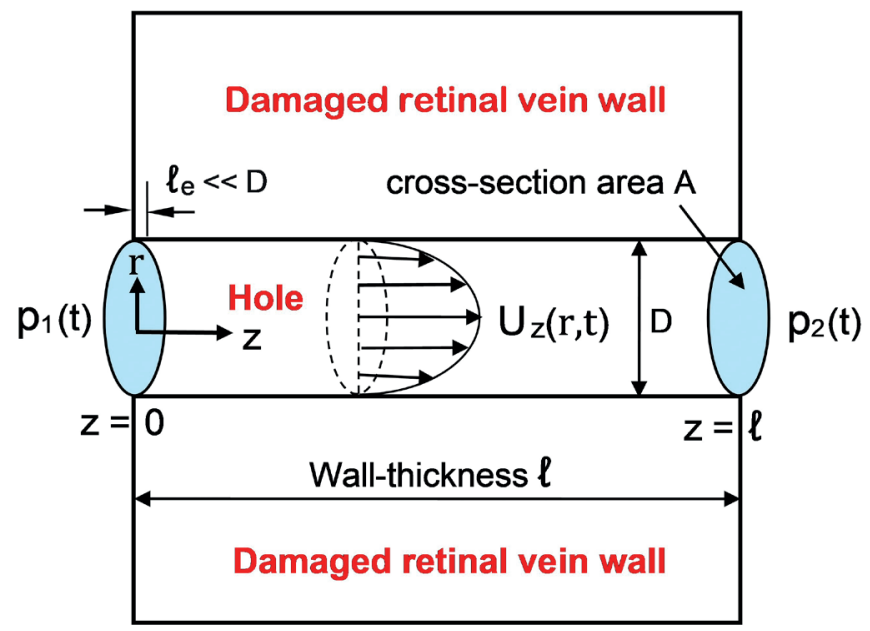

Fig. 3. Schematic diagram of transient leakage flow through a tiny microscopic hole of length $\ell$ in a damaged blood vessel's wall (enlarged for clarity). $\ell$ is also the blood vessel's wall-thickness. The flow is subject to the action of a time-changing positive pressure difference $p_{1}(t)$ - $p_{2}(t)$. Transient fluid velocity $u_{z}(r, t)$ has a fully developed parabolic profile that does not change in the $z$-direction when $z>\ell_{\mathrm{e}}$, where $\ell_{\mathrm{e}}$ is the entrance length.

sels is entirely due to $\mathrm{P}_{\mathrm{VEIN}}(\mathrm{t})-\mathrm{P}_{\mathrm{RET}}(\mathrm{t})$, the transmural drop in mechanical pressure (TDMP). Oncotic pressure differences (OPD) have been ignored because in advanced DR, the OPD plays a much less important role in fluid filtration than the TDMP. The following notes support this assumption. A small vein's wall is a semi-permeable membrane, permeable to water, electrolytes, and small molecules within the blood plasma, but not to large protein molecules such as albumin. This establishes an OPD, i.e., an osmotic pressure difference, opposing the TDMP and proportional to the large molecules' transmural concentration difference. Albumin constitutes about $80 \%$ of the total OPD. In normal small veins, the wall has a low but definite permeability to large molecules such as albumin (p. 409 in Caro et al.), ${ }^{10}$ implying that some pores in the wall allow transport of larger molecules across the wall. In ADR, a much larger number of pores (holes) have abnormally larger diameters, allowing an increased transport of large molecules across the wall. This results in a large fall in concentration difference across the wall, and in a large reduction in oncotic pressure differences.

\subsection{Volume of a fluid droplet leaking into the retina from a single hole in a single heartbeat}

The volume of a tiny microscopic fluid droplet, $\mathrm{V}_{\text {DROPLET }}$, leaking from a single vein's hole during a single heartbeat is derived in this subsection. In a damaged small vein (Fig. 1), consider the leakage flow in a lateral direction from a hole in the feeding 
vein's wall. For simplicity, the hole is viewed as a straight circular pipe of constant cross-section (Fig. 3). In a cylindrical coordinate system ( $r, \theta, z)$, flow velocity components are $\mathrm{u}_{\mathrm{r}}$ (radial), $\mathrm{u}_{\theta}$ (circumferential), and $\mathrm{u}_{\mathrm{z}}$ (axial). Velocities $\mathrm{u}_{\mathrm{r}}$ and $\mathrm{u}_{\theta}$ are taken to be zero (unidirectional flow), and so the focus is on the time-dependent axial velocity $u_{z}(r, t)$, which determines the nature of flow within the hole. For unsteady, unidirectional, axisymmetric, incompressible, and viscous flow, the mass conservation (continuity) and Navier-Stokes equations simplify to (e.g., Batchelor): ${ }^{11}$

Unidirectional axisymetric flow $u_{r}=0, u_{\theta}=0, \frac{\partial u_{z}}{\partial \theta}=0$

Continuity

$$
\frac{\partial u_{z}}{\partial z}=0, \quad \text { implying } u_{z}=u_{z}(r, t)
$$

r, $\theta$ - momentums $\quad \frac{\partial p}{\partial r}=0, \frac{\partial p}{\partial \theta}=0, \quad$ implying $p=p(z, t)$

z- momentum

$$
\rho \frac{\partial u_{z}}{\partial t}=-\frac{\partial p}{\partial z}+\mu \frac{1}{r} \frac{\partial}{\partial r}\left(r \frac{\partial u_{z}}{\partial r}\right)
$$

Here $u_{z}(r, t)$ is axial velocity, $p(z, t)$ is pressure, $\rho$ is fluid density, and $\mu$ is fluid dynamic viscosity. Since neither the first nor the last term in Equation (3b) depends on z, we can write:

$$
\frac{\partial p}{\partial z}=-G(t) \quad(\text { for } G(t)>0, \text { flow is in positive } z \text {-direction })
$$

When $G(t)$ is positive, pressure $p(z, t)$ falls in the positive $z$-direction, driving fluid sideways out of the vein. For any small retinal vein or abnormal hole of diameter $D$, the important Reynolds number is defined by:

$$
R_{e}=\frac{\rho \bar{U} \bar{D}}{\mu}=\frac{\bar{U} D}{v}=\frac{\text { Inertia Forces }}{\text { Viscous Forces }}
$$

where $\rho$ is density, $\bar{U}$ is average flow velocity, $\mu$ is fluid dynamic viscosity, and $v=\mu / \rho$ is fluid kinematic viscosity. Low Reynolds numbers correspond to slow viscous flow in damaged veins and abnormal holes in them. A number of researchers ${ }^{12,13,14,15}$ measured the diameter of venules and capillaries at four macula quadrants of diabetic and non-diabetic human subjects (first two columns in Table 1). Using Equation (5a), corresponding Reynolds numbers for venules and capillaries were calculated for each macular zone (fourth column in Table 1). The averages for the whole macula were:

Non-diabetics: Venule ${ }^{12}$

$\overline{\mathrm{D}}_{v}=105.8$ microns, Venule $\mathrm{R}_{e}=0.053$

Capillary ${ }^{13,14,15}$

$\bar{D}_{c}=6.9$ microns, Capillary $R_{e}=0.0017$

Diabetics: $\quad$ Venule $^{12}$

$\overline{\mathrm{D}}_{v}=110.4$ microns, Venule $\mathrm{R}_{e}=0.055$

Capillary $^{15}$

$\overline{\mathrm{D}}_{c}=6.3$ microns,

Capillary $R_{e}=0.0016$ 
Table 1. Reynolds number, Womersley number, and entrance length in retinal venules and capillaries

\begin{tabular}{|c|c|c|c|c|c|}
\hline \multicolumn{2}{|c|}{$\begin{array}{l}\text { Measured diameters (D) of retinal venules } \\
\text { and capillaries }\end{array}$} & \multirow{2}{*}{$\begin{array}{l}\text { Known }^{10} \\
\text { Average } \\
\text { velocity Ū } \\
(\mathrm{cm} / \mathrm{sec})\end{array}$} & \multicolumn{3}{|c|}{ Calculated flow parameters } \\
\hline Vessel & $\begin{array}{l}\text { Diameter } \\
\text { (micron) }\end{array}$ & & $\begin{array}{l}\text { Reynolds } \\
\text { Number } \\
\text { Re }\end{array}$ & $\begin{array}{l}\text { Womersley } \\
\text { Number } \\
\text { Nw }\end{array}$ & $\begin{array}{l}\text { Entrance } \\
\text { Length } \\
\text { le }=0.06 x \\
D \times R e\end{array}$ \\
\hline \multicolumn{6}{|c|}{ RETINAL BLOOD VESSELS IN NORMALS ${ }^{12}$} \\
\hline $\begin{array}{l}\text { Venule in upper temporal } \\
\text { quadrant }\end{array}$ & 112.6 & 0.2 & 0.056 & 0.080 & $0.0034 \times D$ \\
\hline $\begin{array}{l}\text { Venule in lower temporal } \\
\text { quadrant }\end{array}$ & 107.5 & 0.2 & 0.054 & 0.077 & $0.0032 \times D$ \\
\hline Venule in upper nasal quadrant & 112.7 & 0.2 & 0.056 & 0.081 & $0.0034 \times D$ \\
\hline Venule in lower nasal quadrant & 90.2 & 0.2 & 0.045 & 0.064 & $0.0027 \times D$ \\
\hline Venule averages (of 4 quadrants) & 105.8 & 0.2 & 0.053 & 0.076 & $0.0032 \times D$ \\
\hline $\begin{array}{l}\text { Capillary (average of all retinal } \\
\text { capillaries) }{ }^{13}\end{array}$ & 8.3 & 0.1 & 0.0021 & 0.0059 & $0.00012 \times D$ \\
\hline $\begin{array}{l}\text { Capillary (average of parafoveal } \\
\text { capillaries) }{ }^{15}\end{array}$ & 7.3 & 0.1 & 0.0018 & 0.0052 & $0.00011 \times \mathrm{D}$ \\
\hline $\begin{array}{l}\text { Capillary (near rim of foveal } \\
\text { avascular zone) }{ }^{14}\end{array}$ & 5.1 & 0.1 & 0.0013 & 0.0036 & $0.00008 \times D$ \\
\hline $\begin{array}{l}\text { Capillary averages (of above } \\
\text { three) }\end{array}$ & 6.9 & 0.1 & 0.0017 & 0.0049 & $0.00010 \times D$ \\
\hline \multicolumn{6}{|c|}{ RETINAL BLOOD VESSELS IN DIABETICS ${ }^{12}$} \\
\hline $\begin{array}{l}\text { Venule in upper temporal } \\
\text { quadrant }\end{array}$ & 124.9 & 0.2 & 0.062 & 0.089 & $0.0037 \times \mathrm{D}$ \\
\hline $\begin{array}{l}\text { Venule in lower temporal } \\
\text { quadrant }\end{array}$ & 102.9 & 0.2 & 0.051 & 0.074 & $0.0031 \times D$ \\
\hline Venule in upper nasal quadrant & 117.8 & 0.2 & 0.059 & 0.084 & $0.0035 \times \mathrm{D}$ \\
\hline Venule in lower nasal quadrant & 96.1 & 0.2 & 0.048 & 0.069 & $0.0029 \times D$ \\
\hline Venule averages (of 4 quadrants) & 110.4 & 0.2 & 0.055 & 0.079 & $0.0033 \times D$ \\
\hline $\begin{array}{l}\text { Diabetic capillaries averages - } \\
\text { parafoveal zone }^{15}\end{array}$ & 6.3 & 0.1 & 0.0016 & 0.0045 & $0.00009 \times D$ \\
\hline \multicolumn{6}{|c|}{$12,13,14,15$ are reference numbers; $\operatorname{Re}=\bar{U} \mathrm{D} / \mathrm{V}=$ Reynolds number; $\bar{U}=$ average fluid flow velocit } \\
\hline
\end{tabular}


The diameter of abnormal holes is usually smaller than the diameter of the parent micro-vessels, implying that abnormal holes have Reynolds numbers even smaller than those listed in Equation (5b). Thus, the Reynolds numbers listed in Equation (5b) provide upper bounds for Reynolds numbers in abnormal holes of micro-vessels. For such very small Reynolds numbers $\left(R_{e}<1\right)$, inertia (mass) effects were ignored and inertia term $\partial / \partial t$ was eliminated on the left side of Equation ( $3 \mathrm{~b})$ to give:

$$
\mu \frac{1}{r} \frac{\partial}{\partial r}\left(r \frac{\partial u_{z}}{\partial r}\right)=\frac{\partial p}{\partial z}=-G(t)
$$

The solution of Equation ( $3 c$ ) is found simply by integrating it twice with respect to radius $r$ and applying boundary conditions:

$$
u_{z}(r, t)=-\frac{r^{2}}{4 \mu} G(t)+C_{1} \ln (r)+C_{2}
$$

where $C_{1}$ and $C_{2}$ are integration constants. As $u_{z}$ needs to be finite at the hole's center $(r=0)$, it follows that $C_{1}=0$. The no-slip boundary condition at the hole's wall requires that $u_{z}=0$ at $r=R$ (radius of hole), yielding:

$$
C_{2}=\frac{R^{2}}{4 \mu} G(t) \text {. }
$$

The final expression for the time-dependent pulsatile axial flow velocity $u_{z}$ in abnormal holes is then:

$$
u_{z}(r, t)=\frac{\left(R^{2}-r^{2}\right)}{4 \mu} G(t), z>\ell_{e} \text { (entrance lenght) }
$$

The transient velocity distribution (profile) described by Equation (6c) is Poiseuille in form; it is pulsatile and parabolic at any cross-section along a very short hole (short tube), but not parabolic in the entrance region $0>z<\ell_{e}$. So, Equation (6c) is valid only beyond the very short entrance region shown in Figure 3. Note that the parabolic velocity profile described by Equation (6c) remains unchanged at any z-location. But this z-unchanged velocity profile varies periodically with time during each heartbeat and from heartbeat to heartbeat. When analyzing this unique transient flow in a very short tube, conditions at the entrance region must be given special consideration. The unsteady pulsating flow in the entrance region depends on both Womersley and Reynolds numbers. The Womersley number determines the nature of this unsteady pulsatile flow and is defined by: ${ }^{10}$

$$
\mathrm{N}_{\mathrm{w}}=\frac{\mathrm{D}}{2}\left(\frac{\omega}{\mathrm{v}}\right)^{0.5}=\mathrm{D}\left(\frac{\pi \mathrm{f}}{2 \mathrm{v}}\right)^{0.5}=\frac{\text { Transient Inertia Forces }}{\text { Viscous Forces }}
$$

where $D$ is small vein or abnormal hole diameter in $\mathrm{cm}, \omega$ is the angular frequency of unsteady pulsatile flow in radians $/ \mathrm{sec}(\omega=2 \pi f$, where $f$ is heart rate in cycles $/ \mathrm{sec})$, and $v=0.04$ is kinematic viscosity in $\mathrm{cm}^{2} / \mathrm{sec}$. 
Time-dependent periodic variations in entrance length $\ell_{e}$ occur during the pulsatile cycle. ${ }^{10,16}$ At high values of $N_{w}\left(N_{w}>1\right)$, inertial forces dominate, and these variations can be quite considerable. At very low values of $N_{w}\left(N_{w} \ll 1\right)$, periodic variations in entrance length $\ell_{e}$ can be ignored, because viscous forces dominate, and inertia and time effects can be neglected. For $N_{w} \ll 1$, the entrance length is approximately the same as the steady-state entrance length, primarily dependent on the Reynolds number, and quite well estimated with (e.g., Munson): ${ }^{17}$

$$
\ell_{e}=0.06 \cdot \mathrm{D} \cdot \mathrm{R}_{\mathrm{e}} \text { (laminar flow) }
$$

For retinal venules and capillaries, calculated Womersley numbers in non-diabetics were 0.076 and 0.0049 , respectively, and in diabetics they were 0.079 and 0.0045 , respectively (see fifth column in Table 1). There was no difference between diabetics and non-diabetics. For small abnormal holes in retinal venules or capillaries, Womersley numbers for diabetics are even smaller than 0.079 and 0.0045 , respectively. This makes Equation ( $5 \mathrm{~d}$ ) suitable for entrance length calculations. The 0.079 and 0.0045 values provide upper bounds for $\mathrm{N}_{\mathrm{w}}$ in abnormal holes located in venules and capillaries of diabetics.

Entrance lengths $\ell_{e}$ at various macular quadrants were calculated with Equation (5d) and listed in the last column of Table 1 . For macular venules and capillaries, entrance lengths in non-diabetics were $0.0032 \cdot \mathrm{D}$ and $0.0001 \cdot \mathrm{D}$, respectively, whereas in diabetics they were $0.0033 \cdot \mathrm{D}$ and $0.00009 \cdot \mathrm{D}$, respectively. There was no difference between diabetics and non-diabetics. For holes in venules or capillaries of diabetics, entrance lengths are even shorter than $0.0033 \cdot \mathrm{D}$ and $0.00009 \cdot \mathrm{D}$, respectively. So, entrance length is a very small multiple of the holes' diameter in micro-vessels of diabetics (Fig. 3). The 0.0033. D and 0.00009.D values provide upper bounds for entrance lengths in abnormal holes of macular micro-vessels of diabetics.

For very short entrance lengths $\left(\ell_{e} \ll D\right)$, it was assumed that $\ell_{e} \approx 0$ and that velocity profiles are fully developed and parabolic along the entire $z$-length of the hole. Figure 3 shows the vanishingly small entrance region of a hole. Let $R=1 / 2 D$ be the radius, $A=1 / 4 \pi D^{2}$ the cross-sectional area, and $\ell$ the length of the hole. Note that the hole length $\ell$ is actually the vein's wall-thickness. On the basis of two recent studies, hole-length is on average 18 microns. ${ }^{18,19}$ Solving Equation (4) subject to pressure $\mathrm{p}=\mathrm{p}_{1}(\mathrm{t})$ at $\mathrm{z}=0$ and $\mathrm{p}=\mathrm{p}_{2}(\mathrm{t})$ at $\mathrm{z}=\ell$, yielded the pressure distribution $\mathrm{p}(\mathrm{z}, \mathrm{t})$ along the $z$-direction inside the hole:

$$
\begin{aligned}
& p(z, t)=p_{1}(t)-G(t) z=p_{1}(t)-\frac{\left[p_{1}(t)-p_{2}(t)\right]}{\ell} z \\
& \text { in which } G(t)=\frac{\left[p_{1}(t)-p_{2}(t)\right]}{\ell}
\end{aligned}
$$

At any given instant of time t, pressure drops linearly with $z$ along the hole, but is constant across each cross-section. This linear z-pressure-drop varies, however, 
with time t during a single heartbeat. With $u_{z}(r, t)$ known from Equation (6c), the transient rate of fluid volume leaking from the hole's exit cross-section is given by the time-dependant rate relation:

$$
\mathrm{Q}(t)=\int_{0}^{R} u_{z} 2 \pi r d r=\frac{\pi}{8} \frac{\mathrm{R}^{4}}{\mu} \mathrm{G}(t)=\frac{\pi}{8} \frac{\mathrm{R}^{4}}{\mu l}\left[\mathrm{p}_{1}(t)-\mathrm{p}_{2}(t)\right], \text { for } \mathrm{p}_{1}(t)>\mathrm{p}_{2}(t)
$$

in which we have used Equation (7b). In terms of diameter $D=2 R$, or area $A=\pi R^{2}$, $\mathrm{Q}(\mathrm{t})$ takes the forms:

$$
\mathrm{Q}(t)=\frac{\pi}{128} \frac{D^{4}}{\mu l}\left[\mathrm{p}_{1}(t)-\mathrm{p}_{2}(t)\right]=\frac{1}{8 \pi} \frac{A^{2}}{\mu l}\left[\mathrm{p}_{1}(t)-\mathrm{p}_{2}(t)\right], \text { for } \mathrm{p}_{1}(t)>\mathrm{p}_{2}(t)
$$

Finally, noting that $\mathrm{p}_{1}=\mathrm{P}_{\mathrm{VEIN}}$ and $\mathrm{p}_{2}=\mathrm{P}_{\mathrm{RET}}$, the volume of a single droplet of fluid leaking from the hole's exit cross-section during a single heartbeat is given by:

$$
\begin{aligned}
& V_{\text {DROPLET }}^{\text {LEAK }}=\int_{0}^{T} Q(t) d t=\frac{\pi}{128} \frac{D^{4}}{\mu l} A_{U P C}=\frac{1}{8 \pi} \frac{A^{2}}{\mu l} A_{U P C}, \text { for } P_{\text {VEIN }}(t)>P_{\text {PRET }}(t) \\
& \text { in which } A_{U P C}=\int_{0}^{T}\left[P_{\text {VEIN }}(t)-P_{\text {PRET }}(t)\right] d t, \text { for } P_{\text {VEIN }}(t)>P_{P R E T}(t)
\end{aligned}
$$

Here, $T$ is the duration of a single heartbeat (also known as 'cycle length'), and $A_{U P C}$ is the area under the vein's pressure curve $P_{\text {VEIN }}(t)$, but above retinal interstitial pressure curve $\mathrm{P}_{\text {RET }}(\mathrm{t})$ (colored peaks in Fig. 2).

\subsection{Total fluid volume leaking into the retina from $\mathbf{M}$ holes in $\mathbf{N}$ heartbeats}

Equations are presented below for calculating the total volume of fluid leaking into the retina from a total of $\mathrm{M}$ holes in $\mathrm{N}$ heartbeats. With all holes in retinal blood vessels numbered from 1 to $M$, let $i$ denote hole number $i$ and $j$ heartbeat $j$. In terms of $\mathrm{i}$ and $\mathrm{j}, \mathrm{V}_{\text {DROPLET }}^{\mathrm{LEAK}}$ in Equations (9a and $9 \mathrm{~b}$ ) takes the form:

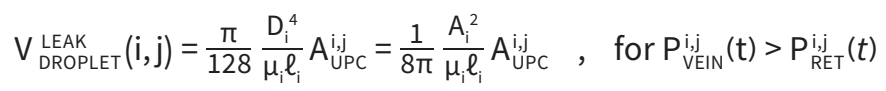

Summing up individual contributions of $\mathrm{V}_{\text {DROPLET }}^{\mathrm{LEAK}}$ from all $\mathrm{M}$ leaking holes, yielded the volume of fluid that leaks into the retina during a single heartbeat $\mathrm{j}$ :

$$
V_{1-B E A T S}^{\text {LEAK }}(j)=\sum_{i=1}^{M} V_{\text {DROPLET }}^{\text {LEAK }}(i, j)=\sum_{i=1}^{M} \frac{\pi}{128} \frac{D_{i}^{4} \mu_{i} \ell_{i}}{A_{U P C}^{i, j}}=\sum_{i=1}^{M} \frac{1}{8 \pi} \frac{A_{i}{ }^{2}}{\mu_{i} \ell_{i}} A_{\text {UPC }}^{i, j} \quad, \quad \text { for } P_{V \in I N}^{i, j,}(t)>P_{\text {RET }}^{i, j}(t)
$$

The total volume of fluid that leaks into the retina from $\mathrm{M}$ holes in $\mathrm{N}$ heartbeat is then:

$$
\begin{aligned}
& V_{N-B E A T S}^{L E A K}=\sum_{j=1}^{N} V_{1-B E A T}^{L E A K}(j)=\sum_{j=1}^{N} \sum_{i=1}^{M} V_{\text {DROPLET }}^{\text {LEAK }}(i, j)=\sum_{j=1}^{N} \sum_{i=1}^{M} \frac{\pi}{128} \frac{D_{i}^{4}}{\mu_{i} \ell_{i}} A_{U P C}^{i, j j}= \\
& =\sum_{j=1}^{N} \sum_{i=1}^{M} \frac{1}{8 \pi} \frac{A_{i}^{2}}{\mu_{i} \ell_{i}} A_{U P C}^{i, j} \quad, \quad \text { for } P_{V \in \mathbb{N}}^{i, j}(t)>P_{R E T}^{i, j j}(t)
\end{aligned}
$$


Volumes of fluid leaking into the retina can also be expressed in terms of averages. The average volume of a fluid droplet leaking into the retina from $\mathrm{M}$ holes during $\mathrm{N}$ heartbeats is:

$$
\bar{V}_{\text {DROPLET }}^{\text {LEAK }}=\frac{1}{N M} \sum_{j=1}^{N} \sum_{i=1}^{M} V_{\text {DROPLET }}^{L E A K}(i, j) \quad, \text { for } P_{V \in I N}^{i, j}(t)>P_{\text {RET }}^{i, j}(t)
$$

Here, NM equals the total number of individual episodes of fluid droplet leakage into the retina. The double sum in Equation (13) equals the total volume of fluid leaking (not accumulating!) into the retina from $\mathrm{M}$ holes in $\mathrm{N}$ heartbeats, i.e., in NM individual leaking episodes. Similarly, the average volume of fluid leaking into the retina from $\mathrm{M}$ holes in a single heartbeat is obtained from Equation (11):

$$
\bar{V}_{1-B E A T}^{L E A K}=\frac{1}{N} \sum_{j=1}^{N} V_{1-B E A T}^{L E A K}(j)=\frac{1}{N} \sum_{j=1}^{N} \sum_{i=1}^{M} V_{D R O P L E T}^{L E A K}(i, j) \quad, \text { for } P_{V \in I N}^{i, j}(t)>P_{R E T}^{i, j}(t)
$$

Putting all this together, the total volume of fluid leaking into the retina from $\mathrm{M}$ holes in $\mathrm{N}$ heartbeats is:

$$
V_{N-B E A T S}^{L E A K}=N \bar{V}_{1-B E A T}^{L E A K}=N M \bar{V}_{\text {DROPLET }}^{L E E A K}=\sum_{j=1}^{N} \sum_{i=1}^{M} V_{\text {DROPLET }}^{L E A K}(i, j) \quad, \text { for } P_{V \in I N}^{i, j}(t)>P_{R E T}^{i, j}(t)
$$

in which all three Equations $(12,13,14)$ were used. Equations (1) to (15) will be called the 'Retinal Fluid Volume Leakage' (RFVL) Equations. The above leakage volumes were calculated from OCT-scans, obtained in five visits to the ophthalmologist, as follows.

\subsection{Macular fluid accumulation, removal, and leakage}

Three processes take place in DR or ADR. Fluid leakage from vein holes ('leakage'), fluid removal from the retina by eye pumps ('pumps'), and fluid accumulation in the retina ('accumulation'). For retinal fluid: Volume accumulated $=$ Volume leaked Volume removed. A similar relation exists for time-rates of accumulation, leakage, and removal. Volume of accumulated fluid is known from two successive OCT-measured macular thicknesses. The unique case of recovery from ADR made it possible to calculate both the rate and volume of fluid removal from the retina by pumps. Leaked fluid volume is then simply the sum of volume accumulated plus volume removed (pumped out).

\subsubsection{Volume of fluid accumulated between OCT scans}

Retinal thickness $\mathrm{H}$ varies from zone to zone in the retina, and so it is measured by OCT at $\mathrm{K}$ different retinal zones of interest. Let $\mathrm{H}_{\mathrm{k}}$ denote average retinal thickness at zone $k$, then average retinal thickness is:

$$
\overline{\mathrm{H}}=\frac{1}{\mathrm{~K}} \sum_{\mathrm{k}=1}^{\mathrm{K}} \mathrm{H}_{\mathrm{k}}
$$


The difference between two OCT measured retinal thicknesses, taken n-days apart, or N-heartbeats apart, is:

$$
\Delta \overline{\mathrm{H}}_{\mathrm{n}}=\overline{\mathrm{H}}_{\mathrm{n}}-\overline{\mathrm{H}}_{0}
$$

in which thickness $\bar{H}_{0}$ is measured on day $n=0$, and thickness $\bar{H}_{n}$ on day $n . \Delta \bar{H}_{n}$ represents excess fluid accumulated in the retina. The volume of accumulated fluid is obtained simply by multiplying $\Delta \overline{\mathrm{H}}_{\mathrm{n}}$ with known retinal surface area S:

$$
\overline{\mathrm{V}}_{\mathrm{n} \text {-days }}^{\text {Acum }}=\mathrm{S} \Delta \overline{\mathrm{H}}_{\mathrm{n}}=\mathrm{S}\left(\overline{\mathrm{H}}_{\mathrm{n}}-\overline{\mathrm{H}}_{0}\right)
$$

Calculation of leaked and removed fluid volumes required prior knowledge of their time-rates of change.

\subsubsection{Daily rates of fluid accumulation, leakage, and removal}

The daily rate at which fluids accumulate in the retina, $\mathrm{Q}_{\mathrm{Acum}}$, equals the difference between the daily rate of fluid inflow, $\mathrm{Q}_{\text {LEAK }}$ (leakage from small veins), and fluid outflow, $\mathrm{Q}_{\text {pump }}$ (removal by pumps), from the retina:

$$
\mathrm{Q}_{\text {ACUM }}=\mathrm{Q}_{\text {LEAK }}-\mathrm{Q}_{\text {PUMP }}\left\{\begin{array}{ll}
\text { Fluid accumulation in diabetics } & \mathrm{Q}_{\text {ACUM }}>0 \\
\text { Non diabetics } & \mathrm{Q}_{\text {ACUM }}=0 \\
\text { Fluid removal in recovering diabetics } & \mathrm{Q}_{\text {ACUM }}<0
\end{array}\right\}
$$

Dividing Equation (18) by $n$, yielded the average daily rate of fluid accumulation $\overline{\mathrm{Q}}_{\text {ACUM }}$ :

$$
\overline{\mathrm{Q}}_{\text {ACUM }} \approx \overline{\mathrm{Q}}_{\mathrm{ACUM}}^{\mathrm{n}}=\overline{\mathrm{Q}}_{\mathrm{LEAK}}^{\mathrm{n}}-\overline{\mathrm{Q}}_{\mathrm{PUMP}}^{\mathrm{n}}=\frac{\overline{\mathrm{V}}_{\mathrm{n} \text {-days }}^{\text {ACUM }}}{\mathrm{n}}=\mathrm{S} \frac{\Delta \overline{\mathrm{H}}_{\mathrm{n}}}{\mathrm{n}}=\mathrm{S} \frac{\overline{\mathrm{H}}_{\mathrm{n}}-\overline{\mathrm{H}}_{0}}{\mathrm{n}}
$$

It required only two known measurements on the right side of Equation (20a) to estimate rate $\overline{\mathrm{Q}}_{\mathrm{Acum}}$. The unique case of 'recovery' from ADR was used to estimate $\bar{Q}_{\text {PUMP. }}$. Consider a diabetic patient recovering from ADR in a period of $\tilde{n}$ days (squiggle denotes 'recovery'). On day $\tilde{n}=0$ of recovery, measured retinal thickness was $\overline{\mathrm{H}}_{\tilde{0}}$, and $\tilde{\mathrm{n}}$ days later it was back to normal at $\overline{\mathrm{H}}_{\infty}$. The rate of fluid leakage into the retina was approximately zero during recovery, and so the eye's pumps reduced retinal thickness from $\overline{\mathrm{H}}_{\tilde{0}}$ to $\overline{\mathrm{H}}_{\infty}$ in $\tilde{n}$ days, and we can write:

$$
\mathrm{n}=\tilde{\mathrm{n}}, \overline{\mathrm{Q}}_{\mathrm{LEAK}}^{\tilde{n}}=0, \overline{\mathrm{H}}_{0}=\overline{\mathrm{H}}_{\tilde{\mathrm{o}}}, \overline{\mathrm{H}}_{\widetilde{\mathrm{n}}}=\overline{\mathrm{H}}_{\infty}
$$

Substituting conditions (20b) into Equation (20a) yielded the formula for estimating average pumping rate $\overline{\mathrm{Q}}_{\mathrm{PUM}}$ :

$$
\overline{\mathrm{Q}}_{\mathrm{PUMP}} \approx \overline{\mathrm{Q}}_{\mathrm{PUMP}}^{\tilde{\tilde{U}}}=-\mathrm{S} \frac{\overline{\mathrm{H}}_{\infty}-\overline{\mathrm{H}}_{\tilde{\sigma}}}{\widetilde{\tilde{n}}}=\mathrm{S} \frac{\overline{\mathrm{H}}_{\tilde{0}}-\overline{\mathrm{H}}_{\infty}}{\widetilde{\tilde{n}}}>0
$$


Only two measurements, $\overline{\mathrm{H}}_{\tilde{0}}$ and $\overline{\mathrm{H}}_{\infty}$, are needed to estimate $\overline{\mathrm{Q}}_{\text {pump. }}$. Note that $\overline{\mathrm{H}}_{\tilde{0}}$ and $\tilde{n}$ are linked. The larger the starting value $\bar{H}_{\tilde{0}}$ is, the longer the $\tilde{n}$-days recovery time to normal $\bar{H}_{\infty}$ will be. Finally, inserting Equation (20c) into Equation (20a) yielded the formula for estimating $\overline{\mathrm{Q}}_{\text {LEAK }}$, the average daily rate of fluid volume leakage into the retina:

$$
\overline{\mathrm{Q}}_{\mathrm{LEAK}} \approx \overline{\mathrm{Q}}_{\mathrm{LEAK}}^{\mathrm{n}}=\overline{\mathrm{Q}}_{\mathrm{ACUM}}^{\mathrm{n}}+\overline{\mathrm{Q}}_{\mathrm{PUMP}}^{\tilde{\mathrm{C}}}=\mathrm{S} \frac{\mathrm{H}_{\mathrm{n}}-\overline{\mathrm{H}}_{0}}{\mathrm{n}}+\mathrm{S} \frac{\overline{\mathrm{H}}_{\tilde{0}}-\overline{\mathrm{H}}_{\infty}}{\widetilde{\tilde{n}}}
$$

Four OCT-measurements, $\overline{\mathrm{H}}_{0}, \overline{\mathrm{H}}_{\mathrm{n}}, \overline{\mathrm{H}}_{\tilde{0}}, \overline{\mathrm{H}}_{\infty}$, were required to estimate $\overline{\mathrm{Q}}_{\text {LEAK }}$ from Equation (20d).

The three rate equations (Eqs. 20 a, c, and d) apply to the whole retina, but were modified for use in the smaller macular region because OCT scans are confined to a macular area of $\mathrm{S}_{\mathrm{m}}=28.274 \mathrm{~mm}^{2}$ within diameter $\mathrm{D}_{\mathrm{m}}=6 \mathrm{~mm}$ (see Introduction). So macular $\overline{\mathrm{Q}}_{\text {ACUM }}, \overline{\mathrm{Q}}_{\mathrm{PUMP}}, \overline{\mathrm{Q}}_{\text {LEAK }}$ were calculated from macular data as follows:

$$
\begin{aligned}
& \overline{\mathrm{Q}}_{\text {ACUM }} \approx \overline{\mathrm{Q}}_{\text {ACUM }}^{\mathrm{n}}=\mathrm{S}_{\mathrm{m}} \frac{\overline{\mathrm{H}}_{\mathrm{n}}-\overline{\mathrm{H}}_{0}}{\mathrm{n}}, \mathrm{S}_{\mathrm{m}}=28.274 \mathrm{~mm}^{2} \\
& \overline{\mathrm{Q}}_{\text {PUMP }}=\overline{\mathrm{Q}}_{\text {PUMP }}^{\widetilde{n}}=\mathrm{S}_{\mathrm{m}} \frac{\overline{\mathrm{H}}_{\tilde{\sigma}}-\overline{\mathrm{H}}_{\infty}}{\widetilde{\mathrm{n}}}, \overline{\mathrm{H}}_{\infty}=\text { normal thickness on day } \widetilde{\mathrm{n}} \\
& \overline{\mathrm{Q}}_{\text {LEAK }}=\overline{\mathrm{Q}}_{\text {ACUM }}+\overline{\mathrm{Q}}_{\mathrm{PUMP}} \approx \overline{\mathrm{Q}}_{\mathrm{LEAK}}^{\mathrm{n}}=\mathrm{S}_{\mathrm{m}} \frac{\overline{\mathrm{H}}_{\mathrm{n}}-\overline{\mathrm{H}}_{0}}{\mathrm{n}}+\mathrm{S}_{\mathrm{m}} \frac{\overline{\mathrm{H}}_{\tilde{\mathrm{O}}}-\overline{\mathrm{H}}_{\infty}}{\widetilde{\mathrm{n}}}
\end{aligned}
$$

\subsubsection{Volumes of fluid removed and leaked between OCT scans}

Multiplying $\overline{\mathrm{Q}}_{\text {PUMP }}, \overline{\mathrm{Q}}_{\text {LEAK }}$ in Equations $(21 \mathrm{~b}, \mathrm{c})$ by $\mathrm{n}$, yielded macular fluid volumes removed by pumps and leaked from vein holes in the $n$-days period between successive scans, respectively:

$$
\begin{aligned}
& \bar{V}_{\text {PUMP }}^{\text {n-days }}=n \bar{Q}_{\text {PUMP }}^{\tilde{n}}=\frac{n}{\widetilde{n}} S_{m}\left(\bar{H}_{\tilde{0}}-\bar{H}_{\infty}\right), \bar{H}_{\infty}=\text { normal thickness on day } \widetilde{n} \\
& \bar{V}_{\text {LEAK }}^{\text {n-days }}=n \bar{Q}_{\text {LEAK }}^{n}=S_{m}\left(\bar{H}_{n}-\bar{H}_{0}\right)+\frac{n}{\widetilde{n}} S_{m}\left(\bar{H}_{\tilde{0}}-\bar{H}_{\infty}\right), \bar{H}_{\infty}=\text { normal thickness on day } \widetilde{n}
\end{aligned}
$$

\subsubsection{Volumes of fluid leaked in N-heartbeats, in 1-heartbeat, and in 1 droplet}

At an average heart rate of $\mathrm{f}$ beats per minute (bpm) (e.g., $78 \mathrm{bpm}=1.3 \mathrm{~Hz})$, the heart beats $\mathrm{N}$ times in $\mathrm{n}$-days:

$$
N=60 \cdot 24 \cdot n \cdot f=1440 \cdot n \cdot f
$$

Since the volumes of fluid leaked in $\mathrm{n}$-days and in $\mathrm{N}$-heartbeats are equal, Equation (22b) can be rewritten as: 


$$
\overline{\mathrm{V}}_{\mathrm{N} \text {-BEATS }}^{\text {LEAK }}=\overline{\mathrm{V}}_{\mathrm{LEAK}}^{\mathrm{n} \text {-days }}=\mathrm{S}_{\mathrm{m}}\left(\overline{\mathrm{H}}_{\mathrm{n}}-\overline{\mathrm{H}}_{0}\right)+\frac{\mathrm{n}}{\widetilde{\mathrm{n}}} \mathrm{S}_{\mathrm{m}}\left(\overline{\mathrm{H}}_{\widetilde{0}}-\overline{\mathrm{H}}_{\infty}\right), \overline{\mathrm{H}}_{\infty}=\text { normal thickness on day } \widetilde{\mathrm{n}}
$$

Inserting Equation (22d) into RFVL Equation (15) yielded:

$$
\begin{array}{r}
\bar{V}_{\mathrm{N}-\mathrm{BEATS}}^{\text {LEAK }}=\mathrm{N} \overline{\mathrm{V}}_{1-\mathrm{BEAT}}^{\mathrm{LEAK}}=\mathrm{NM} \overline{\mathrm{V}}_{\mathrm{DROPLET}}^{\mathrm{LEAK}}=S_{m}\left(\overline{\mathrm{H}}_{\mathrm{n}}-\overline{\mathrm{H}}_{0}\right)+\frac{\mathrm{n}}{\widetilde{\widetilde{n}}} S_{m}\left(\overline{\mathrm{H}}_{\tilde{\mathrm{o}}}-\overline{\mathrm{H}}_{\infty}\right), \\
\bar{H}_{\infty}=\text { normal thickness on day } \widetilde{n}
\end{array}
$$

Finally, rearranging Equation (22e) yielded three separate equations (Eqs. 23a, b, and c) for calculating leaked macular fluid volume in N-heartbeats, in 1-heartbeat, and in 1 droplet from OCT-measured macular thicknesses:

$$
\begin{aligned}
& \bar{V}_{\text {N-BEATS }}^{\text {LEAK }}=S_{m}\left(\bar{H}_{n}-\bar{H}_{0}\right)+\frac{n}{\tilde{n}} S_{m}\left(\bar{H}_{\widetilde{o}}-\bar{H}_{\infty}\right), \bar{H}_{\infty}=\text { normal thickness on day } \widetilde{n} \\
& \bar{V}_{1-B E A T}^{\text {LEAK }}=M \bar{V}_{\text {DROPLET }}^{\text {LEAK }}=\frac{S_{m}}{N}\left(\bar{H}_{n}-\bar{H}_{0}\right)+\frac{n}{\widetilde{n}} \frac{S_{m}}{N}\left(\bar{H}_{\tilde{0}}-\bar{H}_{\infty}\right), \\
& \bar{H}_{\infty}=\text { normal thickness on day } \widetilde{n} \\
& \bar{V}_{\text {DROPLET }}^{\text {LEAK }}=\frac{S_{m}}{N M}\left(\bar{H}_{n}-\bar{H}_{0}\right)+\frac{n}{\widetilde{n}} \frac{S_{m}}{N M}\left(\bar{H}_{\tilde{0}}-\bar{H}_{\infty}\right), \bar{H}_{\infty}=\text { normal thickness on day } \widetilde{n}
\end{aligned}
$$

Fluid volumes leaked in $\mathrm{N}$-beats and in 1-beat were readily calculated from the known right sides of $(23 a, b)$. But $M$ on the right side of Equation (23c) is not yet known, and so $\overline{\mathrm{V}}_{\text {DROPLET }}$ could not be calculated. It could, however, be calculated once $\mathrm{M}$ becomes known in the future. Meanwhile, the important product $\mathrm{M} \overline{\mathrm{V}}_{\text {DROPLET }}$ was computed from the known right side of Equation (23b).

\subsection{Parameters in RFVL equations that control RS in ADR}

From RFVL Equations (9), the volume of a single leaked droplet, $V_{\text {DROPLET }}$, is tightly controlled by $D$ or $A, \mu, \ell$, and $A_{U P C}$. In particular, $V_{D R O P L E T}$ is very sensitive to diameter $D$, or area $A$. It grows with $D$ to the power of 4 , or $A$ to the power of 2 . So, remedies are clearly needed to reduce $D$ or $A$. Furthermore, let $N=N_{R S}$ be the number of heartbeats occurring when significant ADR-induced RS exists. Then RFVL Equations (12) and (15) show that $\mathrm{N}_{\mathrm{RS}}$ and $\mathrm{M}$ also tightly control RS, because the total volume of fluid leaking into retina depends on both $\mathrm{M}$ (number of holes) and $\mathrm{N}=\mathrm{N}_{\mathrm{RS}}$. The larger $\mathrm{M}$ and $\mathrm{N}_{\mathrm{RS}}$ are, the larger excess fluid accumulation in the retina will be. Hence, in $A D R$, the list of clinically significant parameters identified with the RFVL equations includes:

1. $\quad D=$ Diameter of microscopic abnormal hole in a blood vessel's wall;

2. $A=1 / 4 \pi D^{2}=$ Cross-sectional area of a microscopic hole in a blood vessel's wall;

3. $\mu=$ Blood or fluid dynamic viscosity;

4. $\quad \ell=$ Length of abnormal hole, or thickness of blood vessel's wall (Figs. 1 and 3);

5. $A_{\text {UPC }}=$ Area under vein pressure curve $P_{\text {VEIN }}(t)$, but above pressure curve $P_{\text {RET }}$ 
(t) (colored peaks in Fig. 2);

6. $M=$ Total number of abnormal holes in vessels of the retinal micro-circulation; and

7. $\mathrm{N}_{\mathrm{RS}}=$ Number of heartbeats in an ADR period when significant RS exists. The RFVL equations indicate that fluid leakage into the retina will decrease when:

1. $A_{\text {UPC }}$ is decreased as a result of a decrease in transmural pressure $P_{\text {VEIN }}-P_{\text {RET }}$;

2. hole diameter $\mathrm{D}$, or area $\mathrm{A}$, is decreased;

3. blood or fluid viscosity $\mu$ is increased;

4. length of hole $\ell$ is increased;

5. total number $\mathrm{M}$ of leaking holes in retinal blood vessels is decreased; and

6. number of heartbeats $\mathrm{N}_{\mathrm{RS}}$ during significant RS is decreased. Note that hole length $\ell$ is fixed and cannot be increased.

\subsection{Five simple therapeutic treatments that induce recovery from ADR}

During RS, $\overline{\mathrm{Q}}_{\text {LEAK }}>\overline{\mathrm{Q}}_{\text {PUMP }}$ and so fluid accumulates in the retina. It is very difficult to reduce leakage from damaged blood vessels to zero in diabetics. However, this does actually occur, as was mentioned earlier. In general, it is not necessary to aim for $\bar{Q}_{L E A K}=0$. Instead, to reduce swelling, it is sufficient to reduce leakage to levels where $\overline{\mathrm{Q}}_{\text {LEAK }}<\overline{\mathrm{Q}}_{\text {PUMP }}$. With reduced leakage rates below $\overline{\mathrm{Q}}_{\mathrm{PUMP}}$, the eye's pumps take control again and remove excess accumulated fluids until swelling disappears, and retinal thickness is restored to normal. Insights gained from the ADR model were used to design the following five simple therapeutic treatments T1 to T5 for recovery from ADR. Primary author AH applied T1-T5 to treat his ADR, with successful and beneficial outcome.

T1. Use of efficient anti-hypertensive drugs to reduce blood pressure. This can significantly diminish the leakage rate from vein holes due to reduced transmural pressure $\mathrm{P}_{\mathrm{VEIN}}-\mathrm{P}_{\mathrm{RET}}$, and so reduced $\mathrm{A}_{\mathrm{UPC}}$ (Fig. 2).

T2. Increase thiamine intake to a high dose of $300 \mathrm{mg}$ per day so that vitamin B1 levels become normal again..$^{20,21}$ This is expected to help restore retinal veins to good health, 'repair' vein holes, and reduce hole diameter D or area A (see explanatory note below). Ensuring good diabetes control with other medications is also of great importance.

T3. Increase daily vitamin D intake if blood plasma levels are low.

T4. Stop intake of blood thinners such as aspirin (if permissible). This increases blood viscosity and reduces the rate of fluid leakage from holes in retinal blood vessels.

T5. Reduce daily consumption of cups of coffee.

\subsubsection{Explanatory notes on T1-T5}

Treatment T1: In hypertensive diabetics suffering from ADR, efficient anti-hypertensive drug therapy can cause both arterial and venous temporal blood pressure 
fluctuations to drop to almost normal levels. Inserting a much-downsized oscillatory pressure $P_{\text {veIN }}(t)$ into Equations (9) results in greatly diminished $A_{U P C}$ and in much-reduced fluid leakages into the retina. Leakage could even come to a complete halt when $A_{u P C}$ is zero or very close to zero.

Treatment T2: Thiamine (vitamin B1) is an essential co-factor involved in cellular metabolism. It plays a fundamental role in intracellular glucose metabolism. ${ }^{22}$ Given that humans cannot synthesize thiamine, a regular intake of thiamine from external sources (yeasts and plants) is needed to maintain normal body storage levels. The average daily nutritional intake of vitamin B1 is only $1 \mathrm{mg}$. In diabetics, thiamine's various roles can prevent toxic cellular changes induced by hyperglycemia (high glucose levels) from taking place. ${ }^{22}$ Several studies have shown that type 1 and 2 diabetics suffer from thiamine deficiency. ${ }^{20,24,23}$ Lack of thiamine can cause a number of severe vascular disorders that result in, for example, retina, kidney, and nerve damage, as well as heart disease and stroke. In the thiamine-deficient state, glucose undergoes metabolism via alternate pathways (that are not thiamine-dependent), leading to formation of harmful by-products that can damage blood vessels and induce ADR. In addition, thiamine has direct action on the insulin-secreting function of the pancreas, and therefore, thiamine deficiency may contribute to hyperglycemia through mechanisms other than impaired glucose metabolism. Thiamine supplementation can counteract the damaging effects of hyperglycemia on retinal blood vessels. It does this by preventing formation of harmful by-products produced by glucose metabolism via alternate thiamine-independent pathways, as well as by restoring pancreatic function to normal. Supplementation of thiamine analogues in animal models of diabetes has, indeed, been shown to prevent DR disease progression..$^{25,26}$

Hence, supplementary thiamine is key to warding off retinal vascular problems and ADR. In human diabetics, the simple link between thiamine deficiency and diabetes complications was demonstrated by Thornalley and his team. ${ }^{20,23}$ They measured thiamine levels in blood plasma and found that concentrations were $76 \%$ lower than normal in type 1 diabetics and 75\% lower in type 2 diabetics. They also found that type 1 and 2 diabetics expelled thiamine from their bodies at 15 times the normal rate. To keep blood vessels in good health, diabetics with low vitamin B1 levels clearly need additional thiamine intake to return vitamin B1 levels to normal. Since daily nutritional intake of vitamin B1 is only $1 \mathrm{mg}$, changes to diet would not be enough to have an effect. Accordingly, Thornalley successfully treated his diabetic patients with a high-dose of $300 \mathrm{mg}$ vitamin B1 daily. ${ }^{20,21}$

Treatment T3: The relationship between vitamin D deficiency (VDD) and DR has most recently (October 2016) been reviewed. ${ }^{27}$ Evidence is strongly suggestive that significant VDD is present in both type 1 and 2 diabetics, compared to non-diabetics, and of $a$ link between VDD and the severity of DR. ${ }^{28}$ VDD has also been associated with increased odds of age-related macular degeneration, ${ }^{29}$ which is the most 
common cause of blindness in the elderly. Since vitamin D plays many important and beneficial roles in our eyes and bodies, ${ }^{30}$ it was expected that a substantial vitamin D intake (below toxic levels) may help 'repair' and reduce diameter D and area $A$ of holes in retinal veins.

Treatment T4: Aspirin is an antiplatelet drug (anti-aggregant) that decreases platelet aggregation and inhibits thrombus formation. Aspirin is widely used in primary and secondary prevention of thrombotic cardiovascular disease, and has demonstrated mortality benefit in prevention of cardiovascular death in specific populations. The American Heart Association (AHA) recommends that people at high risk of heart attack should take a daily low-dose of aspirin, and that heart attack survivors regularly take low-dose aspirin. Many individuals follow the AHA's advice, and even individuals at no risk of heart attack also take daily low-dose aspirin as a preventive measure. The blood-thinning effects of aspirin have traditionally been ascribed to antiplatelet mechanisms. Aspirin has more recently been demonstrated to lower blood viscosity. Though various mechanisms have been proposed, aspirin-induced changes to the erythrocyte cell membrane were shown to decrease red blood cell rigidity, and to decrease whole blood viscosity. ${ }^{31}$ In 2008 , Vekasi ${ }^{32}$ demonstrated a relationship between aspirin use and lowered blood viscosity in patients with DR. So, stopping aspirin intake leads to an increase in blood viscosity $\mu$, which in turn, reduces the rate of fluid leakage $Q(t)$ from vein holes into the retina. The reduced leakage rate is due to the inverse relationship between $\mathrm{Q}(\mathrm{t})$ and $\mu$, defined in Equations (8). The higher the viscosity, the lesser the rate (and volume) of fluid leaking into the retina from holes in damaged veins. A simple intuitive example illustrates the effect that viscosity has on leakage flow. Compare a short-duration burst of low-viscosity water flowing from the end of a garden hose with a short burst of viscous oil flowing from the end of the same hose. A small amount of oil will land next to your feet, while a much larger volume of water will land a few meters further away. The higher the viscosity, the lesser the volume of fluid ejected from the end of the hose will be.

Treatment T5: Caffeine can cause a short, but dramatic, increase in blood pressure, even in subjects with normal blood pressure. It is unclear what causes this spike in blood pressure (Mayo Clinic). ${ }^{34}$ Being a mathematician, AH consumed between 10 to 15 cups of coffee daily. This has been reduced to only 2-3 cups daily, with long-term beneficial effects.

\section{Results}

Primary author AH has had type 2 diabetes for 43 years, and in the distant past suffered from ADR. He successfully treated his ADR with T1-T5, and has now been free of ADR for over ten years. From mid-2004 (13.5 years ago), AH's retinas 
continued swelling despite laser treatments, eventually reaching 477 microns by June 28, 2007. As laser therapy had become ineffective, and offers of intra-vitreal Avastin injections were most unappealing, AH turned to mathematics, rather than medicine, to find new effective treatments for his ADR and impaired (blurred) vision. With a sense of great urgency attributed to fear of fast-approaching blindness, and while still being able to see modestly well, AH derived the above mathematical model of ADR and treatments T1-T5 ten years ago. (Writing of this paper also the started ten years ago.) Simultaneous application of treatments T1-T5 started at the end of June 2007. Remarkably, after only 42 days, AH's retinal thickness returned to normal and stayed normal ever since, without Avastin injections. Noteworthy was some detectable vision improvement 11 days after initiation of T1-T5. Treatments T1-T5 have clearly diminished fluid leakage in AH's retinas, and achieved a long-lasting recovery from ADR. It is not possible to select the most effective of T1-T5. All of them have probably combined to reduce retinal thickness to normal and keep it normal up to this day.

\subsection{Advancing DR and recovery from $A D R$}

Table 2 summarizes results of calculations with fluid leakage equations derived earlier. Calculations were based on five OCT thicknesses, measured on five visits to the ophthalmologist. DR advanced to unmanageable levels between Visits 1 and 4, while recovery from ADR occurred between Visits 4 and 5. Rows 1 and 2 in Table 2 list OCT scan number (visit number) and date, respectively. Row 3 lists n (number of days between two successive scans) and $\tilde{n}$ (number of days needed to recover from ADR). Measured macular thicknesses are tabulated in row 4, and corresponding macular volumes in row 6 . On Visit 1, macular volume was $7.590 \mathrm{~mm}^{3}$ and on Visit 4 it was $13.487 \mathrm{~mm}^{3}$, but on Visit 5 it was almost normal at $7.04 \mathrm{~mm}^{3}$. Accumulated fluid volumes, calculated from Equation (18) with $S=S_{m}$, are listed in row 7. Dividing them by $n$ or $\tilde{n}$ yielded $\bar{Q}_{A c u m}$, the average daily rates of fluid volume accumulation in the macula (row 8). Between Scans 2 and 3, $\bar{Q}_{\text {Acum }}$ was $44.01 \times 10^{-4} \mathrm{~mm}^{3} /$ day. But between Scans 3 and $4, \bar{Q}_{\text {Acum }}$ had a huge jump to $848.22 \times 10^{-4} \mathrm{~mm}^{3} /$ day (a 19-fold hike) in only 28 days. Happily, between Scans 4 and $5, \overline{\mathrm{Q}}_{\text {Acum }}$ became negative at $-1534.87 \times 10^{-4} \mathrm{~mm}^{3} /$ day due to the pumps regaining control and removing fluids from a macula in recovery from ADR. The rate of fluid volume removal by pumps (pumping rate) was found to be high: $\overline{\mathrm{Q}}_{\text {PuMP }}=1534.87 \times 10^{-4} \mathrm{~mm} /$ day; calculated from Equation (21b) with $\bar{H}_{\infty}=0.249 \mathrm{~mm}$. This reveals a previously 'hidden' capacity of eye pumps to clear macular fluids at very substantial rates (discusssed in more depth in the next section).

Under 'emergency' conditions prevailing in ADR, the eye's pumping apparatus operates at, or close, to full capacity. It was therefore assumed that, in ADR, pumping rate is constant and about maximal, with magnitude dictated by pathological conditions prevailing in ADR. This rate was then applied in previous four inter-scans periods (row 9). 
Leakage rates, $\overline{\mathrm{Q}}_{\text {LEAK }}$, were calculated with Equation (21c) and tabulated in row 10. Between Scans 1 and 2 and between 2 and $3, \bar{Q}_{\text {LEAK }}$ and $\bar{Q}_{\text {PUMP }}$ were almost identical, and so a modest volume of fluid accumulated in the macula in these periods. A large increase in leakage rate to $0.23831 \mathrm{~mm}^{3} /$ day $(51 \%$ higher than the previous rate) occurred between Scans 3 and 4. Its significance is analyzed in the next subsection. Actual volumes $\left(\mathrm{mm}^{3}\right)$ of removed fluid and leaked fluid for all inter-scan periods are tabulated in rows 11 and 12, respectively. Expressing these volumes in multiples of $\bar{V}_{m \infty}=6.76 \mathrm{~mm}^{3}$ (rows 13,14 ), showed that the volume of fluid leaked in 28 days between Scans 3 and 4 was $1.0 \bar{V}_{\text {mo }}$, while fluid volume removed in 42 days of recovery from ADR (inter-scans 4-5) was also $1.0 \bar{V}_{m \infty}$. Thus, fluid volumes equivalent to the volume of an entire macula were leaked and removed in two brief and crucial inter-scan periods!

Finally, at an average heart rate of $78 \mathrm{bpm}(1.3 \mathrm{~Hz})$, the number of heartbeats $\mathrm{N}$ in each inter-scan period is listed in row 16. Inserting $N$ into Equation (23b) yielded the important product $M \bar{V}_{\text {DROPLET }}^{\text {LEAK }}=\bar{V}_{1 \text {-BEAT }}^{\mathrm{LEAK}}$ for all inter-scan periods (row 17). Between Scans 1 and 3, leaked $M \bar{V}_{\text {DROPLET }}^{\text {LEAK }}$ averaged $1.385 \mathrm{~mm}^{3} \times 10^{-6}$. But in the next 28 days (inter-scans 3-4), it grew by a hefty $53.2 \%$ to $2.122 \mathrm{~mm}^{3} \times 10^{-6}$, and then dropped to zero in the 42 days of recovery from ADR. The significance of the large rise and large fall in $M \bar{V}_{\text {DROPLET }}^{\text {LEAK }}$ is explained in the next two subsections.

\subsection{Profound effect of small changes in hole diameter on fluid leakage}

Because of shortness of inter-scan period 3-4 (only 28 days), it is unlikely that $M$ (number of holes) had risen sharply in this short period. Hence, the large rise in product $M V_{\text {DROPLET }}^{L E A K}$ was likely due to a large increase in leaked droplet volume, $\mathrm{V}_{\text {DROPLET }}^{\mathrm{LEAK}}$, and not due to M. Two parameters in $\mathrm{V}_{\text {DROPLET }}^{\mathrm{LEAK}}$ Equations (9) and (10) could have varied sharply in a short time; diameter $D$ and area under the pressure curve $A_{\text {upc }}$. Since AH's medications were inefficient in controlling his hypertension for more than a year, his already large $A_{U P C}$ was not likely to explain the large rise in $V_{\text {DROPLET }}^{\text {LEAK }}$. An increase in hole diameter $D$ is then the likely cause for the large rise in $V_{\text {DROPLET }}^{\text {LEAK }}$, as explained below.

For a fixed number of holes $\mathrm{M}$, from smallest to largest, let the diameter of each hole be expanded $(\varphi>0)$ or contracted $(\varphi<0)$ by a factor $\varphi$. Then we can write:

$$
\frac{D_{i}^{\varphi}}{D_{i}}=\varphi \text { for } i=1,2,3, \ldots ., M
$$

where $D_{i}$ is the original hole diameter, and $D_{i}^{\varphi}$ is the enlarged or contracted diameter of hole $i$. It is assumed that no other changes take place. Substituting Equation (24a) into Equations (10) and (13) shows that mean leaked droplet volume increases or decreases by a factor of $\varphi^{4}$ to give:

$$
\frac{\bar{V}_{\text {DROLLET }}^{\text {LEAK }}}{\overline{\mathrm{V}}_{\text {DROPLLET }}^{\text {LEA }}}=\varphi^{4}
$$


Table 2. Results of calculations with ADR model

\begin{tabular}{|c|c|c|c|c|}
\hline \multirow[b]{2}{*}{ Macular parameter } & \multicolumn{2}{|c|}{ Symbols and equations } & \multicolumn{2}{|l|}{ ADR } \\
\hline & $\begin{array}{l}\text { Symbol or } \\
\text { formula }\end{array}$ & $\begin{array}{l}\text { Equation and/or } \\
\text { Equation number }\end{array}$ & $\begin{array}{l}\text { OCT } \\
\text { scan }\end{array}$ & $\begin{array}{l}\text { Inter-scan } \\
\text { parameters }\end{array}$ \\
\hline OCT scan or visit number & & & 1 & \\
\hline Date of scan & & & 05-Nov- 04 & \\
\hline Number of inter-scans days & nor $\tilde{n}$ & & & $n=130$ \\
\hline Macular thickness (mm) & $\overline{\mathrm{H}}$ & & 0.268 & \\
\hline Macular surface area $\left(\mathrm{mm}^{2}\right)$ & $\mathrm{S}=\mathrm{S}_{\mathrm{m}}$ & & 28.274 & \\
\hline Macular volume $\left(\mathrm{mm}^{3}\right)$ & $\nabla_{m}$ & $S_{m} \bar{H}$ & 7.590 & \\
\hline $\begin{array}{l}\text { Volume of fluid Accumulated } \\
\text { between scans }\left(\mathrm{mm}^{3}\right)\end{array}$ & $\nabla_{\text {n-days }}^{\text {Acum }}$ & Eq. (18) & & -0.03 \\
\hline $\begin{array}{l}\text { Rate of fluid volume } \\
\text { Accummulation }\left(10^{4} \times \mathrm{mm}^{3} / \text { day }\right)\end{array}$ & $\overline{\mathrm{Q}}_{\mathrm{ACUM}}$ & Eq. (21a) $\frac{1}{n} \bar{V}_{n \text {-days }}^{\text {ACum }}$ & & -2.31 \\
\hline $\begin{array}{l}\text { Rate of fluid volume Removal } \\
\left(10^{4} \times \mathrm{mm}^{3} / \text { day }\right)\end{array}$ & $\overline{\mathrm{Q}}_{\mathrm{PUMP}}$ & Eq. (21b) & & 1534.87 \\
\hline $\begin{array}{l}\text { Rate of fluid volume Leakage } \\
\left(10^{4} \times \mathrm{mm}^{3} / \text { day }\right)\end{array}$ & $\overline{\mathrm{Q}}_{\mathrm{LEAK}}$ & $\begin{array}{c}\text { Eq. }(21 \mathrm{c}) \\
\overline{\mathrm{Q}}_{\text {ACUM }}+\overline{\mathrm{Q}}_{\mathrm{PUMP}}\end{array}$ & & 1532.57 \\
\hline $\begin{array}{l}\text { Volume of fluid Removed } \\
\text { between scans }\left(\mathrm{mm}^{3}\right)\end{array}$ & $\overline{\mathrm{V}}_{\mathrm{n} \text {-days }}^{\text {PUMP }}$ & $n \overline{\mathrm{Q}}_{\text {PUMP }}$ & & 19.95 \\
\hline $\begin{array}{l}\text { Volume of fluid Leaked } \\
\text { between scans }\left(\mathrm{mm}^{3}\right)\end{array}$ & $\nabla_{n \text {-days }}^{\text {LEAK }}$ & $\mathrm{n} \overline{\mathrm{Q}}_{\mathrm{LEAK}}$ & & 19.92 \\
\hline $\begin{array}{l}\text { Volume of fluid Removed in } \\
\text { multiples of } \bar{\nabla}_{m \infty}\end{array}$ & $\overline{\mathrm{V}}_{\mathrm{n} \text {-days }}^{\text {PUMP }} / \overline{\mathrm{V}}_{\mathrm{m} \infty}$ & & & 3.0 \\
\hline $\begin{array}{l}\text { Volume of fluid Leaked in } \\
\text { multiples of } \bar{V}_{m \infty}\end{array}$ & $\overline{\mathrm{V}}_{\mathrm{n} \text {-days }}^{\mathrm{LEAK}} / \overline{\mathrm{V}}_{\mathrm{m} \infty}$ & & & 2.9 \\
\hline Average heart rate (bpm) & $f$ & & & 78 \\
\hline $\begin{array}{l}\text { Number of heartbeats } \\
\text { between successive scans }\end{array}$ & $\mathrm{N}$ & $60 \cdot 24 \cdot n \cdot f$ & & $14,601,600$ \\
\hline $\begin{array}{l}\mathrm{MV}_{\text {DROPLET }}=\mathrm{V}_{1-\mathrm{BEAT}}^{\mathrm{LEAK}} \\
\text { product in } \mathrm{mm}^{3} \times 10^{6}\end{array}$ & $n \overline{\mathrm{Q}}_{\mathrm{LEAK}} / \mathrm{N}$ & Eq. $(23 b)$ & & 1.364 \\
\hline
\end{tabular}

$\bar{V}_{m \infty}=6.76 \mathrm{~mm} 3=$ mean macular volume in normal subjects; ADR = advanced diabetic retinopathy; $\tilde{n}=42$ = number of days in recovery from ADR (inter-scans 4-5) 


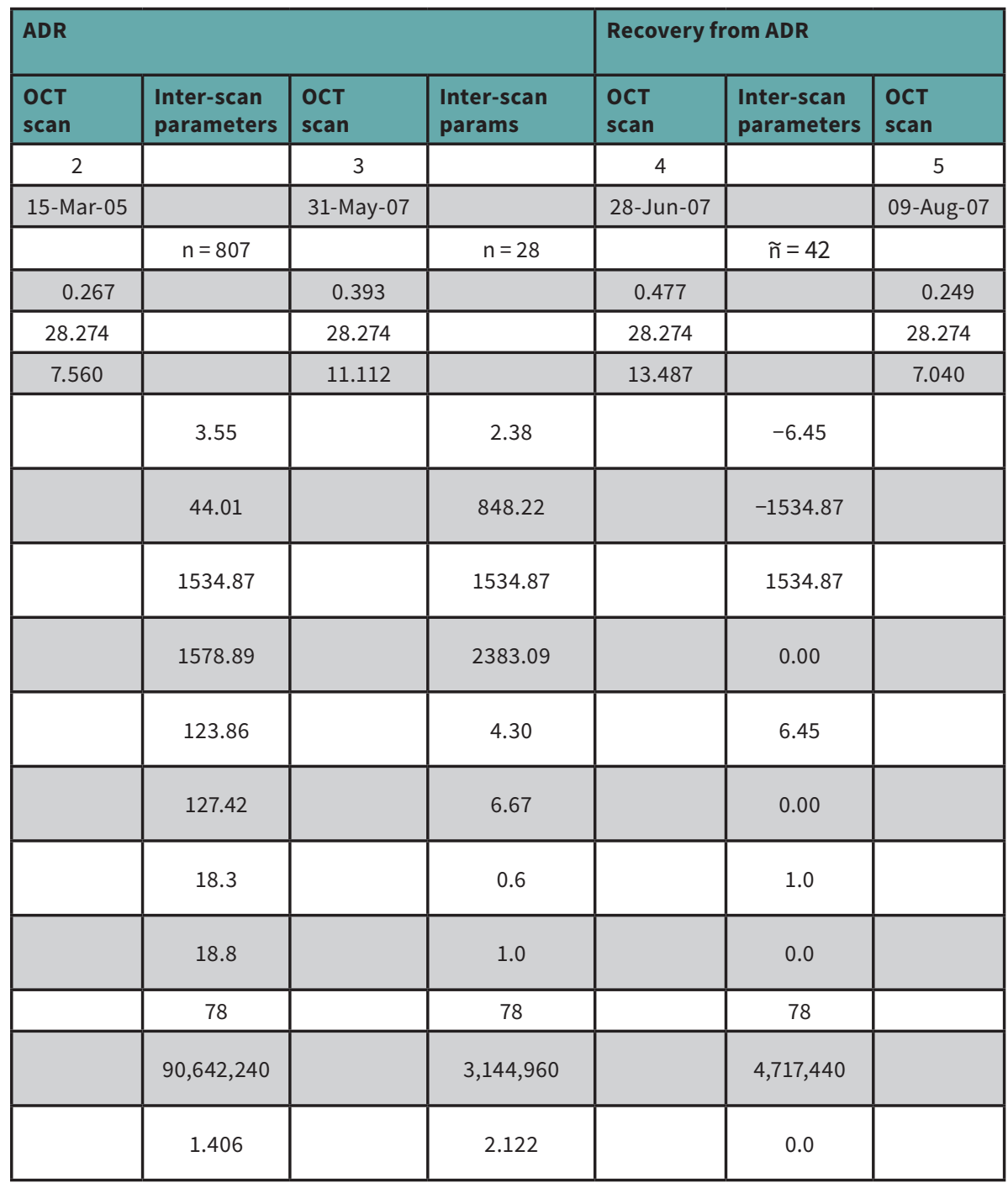


$\mathrm{MV}_{\text {DROPLET }}^{\text {LEAK }}$ was $1.406 \cdot 10^{-6} \mathrm{~mm}^{3}$ and $2.122 \cdot 10^{-6} \mathrm{~mm}^{3}$ in inter-scan periods $2-3$ and $3-4$ (Table 2). Dividing them gives:

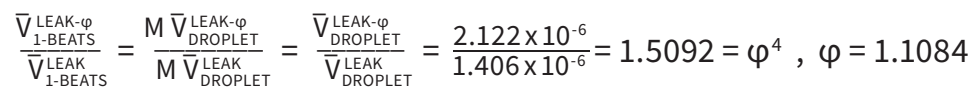

Thus, a mere $10.84 \%$ increase in the diameters of all holes $(\varphi=1.1084)$ produced an impressive $50.9 \%$ increase in mean leaked droplet volume. This exposes the profound effect that small increases in hole diameters $D$ have on volume of leaked fluid droplets in ADR. This may also explain AH's vision problems in the inter-scan period 3-4. Often, large leakages originate from a few large micro-aneurysms. The above analysis applies to them as well, because mean leaked droplet volume is calculated from a distribution of hole diameters, ranging from 'small-leaking', small-diameter holes to 'big-leaking', large-diameter holes. They all had their diameter enlarged by a factor $\varphi$.

Diameter contraction $(\varphi<1)$ probably takes place during recovery from ADR. A modest $-8.5 \%$ reduction in all diameters $D(\varphi=0.915)$ will result in a large $-30.0 \%$ $\left(0.915^{4}-1\right)$ reduction in fluid leakage into the macula. This is both impressive and clinically significant. It means that shrinkage in hole diameters may only need to be small, or modest, to be highly effective in reducing ADR swelling. In AH's case, it is possible that treatments T2 (vitamin B1) and T3 (vitamin D) induced small 'repairs' in AH's retinal blood vessels, resulting in modest 'shrinking' of hole diameters, and in sustained recovery from ADR.

Table 3 lists $\varphi^{4}-1$ values (relative increase or decrease in leakage volume) for a range of expansion and contraction factors $\varphi$. In ADR, small to modest increases of $2.4 \%, 5.7 \%, 10.7 \%, 15 \%$, and $19 \%$ in hole diameters induce impressive $10 \%, 25 \%$, $50 \%, 75 \%, 100 \%$ (volume-doubling) increases in leakage-volumes, respectively, In recovery from $A D R$, small to modest decreases of $-2.6 \%,-5.4 \%,-8.5 \%,-12 \%$, and $-15.9 \%$ in hole diameters induce equally impressive $-10 \%,-20 \%,-30 \%,-40 \%$, and $-50 \%$ decreases in leakage volumes, respectively. The $-50 \%$ decrease constitutes an awe-inspiring halving in fluid leakage during recovery from ADR. Since it takes time for the eyes to 'repair' and restore blood vessels to good health, hole 'shrinkage' is probably not a fast process.

\subsection{Reducing RS in ADR with efficient anti-hypertensive drugs}

AH's blurred vision improved slightly, but noticeably, after only 11 days on more efficient anti-hypertensive drugs. In the recovery from ADR period, only parameter $A_{u P C}$ in droplet volume Equations (9) and (10) could respond in just 11 days. When $A_{u p C}$ becomes zero due to the action of efficient drugs, the pressure force driving fluids through holes vanishes, and leakage flow soon comes to a halt. Thus, in the first 11 days of recovery, the pumps probably succeeded in partially reducing AH's macular volume, which explains his slight but noticeable vision improvement. It is tempting to speculate that all that needs to be done to achieve recovery from ADR 
Table 3. Large changes in volume of fluid leaking into the macula in response to small changes in diameters of holes in macular blood vessels

\begin{tabular}{|c|c|c|c|c|c|c|c|c|c|c|c|}
\hline \multirow{2}{*}{$\begin{array}{l}\text { Macula } \\
\text { parameter }\end{array}$} & \multirow{2}{*}{$\begin{array}{l}\text { Equation } \\
\frac{D_{i}^{\varphi}}{D_{i}}=\varphi\end{array}$} & \multicolumn{5}{|c|}{ Recovery from DR or ADR } & \multicolumn{5}{|c|}{ Advancing DR } \\
\hline & & 0.841 & 0.880 & 0.915 & 0.946 & 0.974 & 1.024 & 1.057 & 1.107 & 1.150 & 1.190 \\
\hline $\begin{array}{l}\text { Relative } \\
\text { volume } \\
\text { of fluid } \\
\text { leaking into } \\
\text { the macula }\end{array}$ & $\varphi^{4}$ & 0.500 & 0.600 & 0.701 & 0.801 & 0.900 & 1.100 & 1.248 & 1.502 & 1.749 & 2.005 \\
\hline $\begin{array}{l}\text { Relative } \\
\text { increase or } \\
\text { decrease } \\
\text { in hole } \\
\text { diameter }\end{array}$ & $\varphi-1$ & $-15.9 \%$ & $-12.0 \%$ & $-8.5 \%$ & $-5.4 \%$ & $-2.6 \%$ & $2.4 \%$ & $5.7 \%$ & $10.7 \%$ & $15.0 \%$ & $19.0 \%$ \\
\hline $\begin{array}{l}\text { Relative } \\
\text { increase or } \\
\text { decrease } \\
\text { in volume } \\
\text { of fluid } \\
\text { leaking into } \\
\text { the macula. }\end{array}$ & $\varphi^{4}-1$ & $-50.0 \%$ & $-40.0 \%$ & $-29.9 \%$ & $-19.9 \%$ & $-10.0 \%$ & $10.0 \%$ & $24.8 \%$ & $50.2 \%$ & $74.9 \%$ & $100.5 \%$ \\
\hline
\end{tabular}

$D_{i}=$ original hole diameter; $D_{i}^{\varphi}=$ expanded or contracted hole diameter; $i=1,2,3, \ldots, M$; $M=$ number of holes in macular blood vessels

is to efficiently control BP. Sadly, this is only helpful in reducing macular swelling for about four to five years, but not in halting progression of ADR and further damage to retinal blood vessels. ${ }^{33}$ Additional treatments to T1, e.g., T2 to T5, may help 'repair' damaged vessels and sustain ADR recovery.

\section{Discussion and conclusions}

This paper asserts usefulness of mathematics in finding new ways of avoiding blindness in diabetics. A mathematical model of ADR, based on fluid leakage from retinal micro-vessels, was used to design five alternative treatments, T1-T5, to recover from ADR. AH treated his ADR with T1-T5, with very successful and beneficial outcome; he recovered from ADR in six weeks, and has been free of ADR for over ten years. Treatments T1-T5 are not a proven 'cure' for ADR, because they are based on a 
single patient application of T1-T5. However, successful and 'fruitful' single reports are often the basis for initiating medical trials based on numerous observations. It is, therefore, hoped that future clinical trials will confirm that treatments T1-T5 can achieve sustained recovery from ADR.

Progression of AH's ADR was halted because all five treatments T1 to T5 were applied simultaneously. Applying T1 alone (efficient BP control) is not sufficient to achieve a durable outcome since benefits last for only four to five years. ${ }^{33}$ Treatments T2-T5 must be applied together with T1 to achieve long-lasting freedom from DR or ADR.

The unique case of recovery from ADR allowed calculation of the hitherto 'hidden' and unknown pumping rate $\overline{\mathrm{Q}}_{\text {PuMP. }}$. During recovery, leakage rates are almost zero, and so the rate of macular volume 'shrinkage' is solely determined by $\overline{\mathrm{Q}}_{\text {PUMP. }}$. This rate is colossal; $\bar{Q}_{\text {PUMP }}=0.1535 \mathrm{~mm}^{3} /$ day. At this rate, eye pumps can remove an entire normal macula-volume-equivalent in 44 days $\left(6.76 \mathrm{~mm}^{3} / 0.1535 \mathrm{~mm}^{3} /\right.$ day). This actually happened during AH's recovery from ADR; a volume of $6.45 \mathrm{~mm}^{3}$ (close to $1.0 \overline{\mathrm{V}}_{\mathrm{mo}}$ ) was cleared in 42 days (row 13 in Table 2). By any measure, this is a very large fluid volume for such microscopic pumps. $\overline{\mathrm{Q}}_{\text {pump }}$ can vary, of course, from one diabetic subject to another. In mild DR, eye pumps can easily remove average-sized leakages from the macula. In severe ADR, pumps get overpowered by leakage rates markedly higher than $\overline{\mathrm{Q}}_{\mathrm{PUMP}}$, and so significant macular swelling occurs. To reduce swelling and recover from ADR, all that needs to be done is reduce leakage rates to below $\overline{\mathrm{Q}}_{\mathrm{PUMP}}$. This applies to all diabetics, each with its own $\overline{\mathrm{Q}}_{\mathrm{PUMP}}$.

The actual volume of fluid that leaked $\left(n \overline{\mathrm{Q}}_{\text {LEAK }}\right)$ in the short 28 days period of severe ADR was huge: $1.0 \bar{V}_{m \infty}$ (inter-scans 3-4, row 14). Thus, in severe ADR and also in recovery from $A D R$, whole macula-volume-equivalents were leaked then removed (see above) in two successive, short, and crucial inter-scan periods.

At present, $M$ (total number of holes in retinal blood vessels) is not known. But when it is finally measured in the future, it may serve as a useful index in clinical assessment of progression or recovery from DR or ADR.

Finally, leakage volumes are very sensitive to small changes in hole-diameters. A small $5.7 \%$ increase, or a $-5.4 \%$ decrease, in hole diameter results in a sizeable $25 \%$ increase or a $-20 \%$ decrease in leakage volumes, respectively. A modest $19 \%$ increase, or a $-15.9 \%$ decrease, results in massive doubling or halving of leakage volumes, respectively (Table 3). With such sensitivity, advancing DR can easily become unmanageable, while long-lasting recovery from ADR may be achievable in less than two months with efficient BP control and small 'repairs' to blood vessels. These 'repairs' lead to modest shrinkage in hole diameters, and to much diminished leakage from shrunken holes. It is speculated that long-term sustained recovery from ADR may be greatly assisted by treatments T2 (vitamin B1) and T3 (vitamin D). These vitamins may induce holes shrinkage, which needs only be modest to be effective! In some diabetics already blinded by ADR; treatments T1-T5 may, hopefully, succeed in restoring their sight, since this only entails pumping fluids out of very thick retinas. 


\section{References}

1. Dirani M. Out of sight. A report into diabetic eye disease in Australia. Australia: Co-published by the Baker IDI Heart and Diabetes Institute and the Centre for Eye Research; 2013. Available from: https:// www.cera.org.au/wp-content/uploads/2015/11/OutOfSightReport.pdf.

2. Lee R, TY Wong, C Sabanayagam. Review: Epidemiology of diabetic retinopathy, diabetic macular edema and related vision loss. Eye Vis. 2015;2(17):1-25. doi: 10.1186/s40662-015-0026-2.

3. Wu G. Diabetic retinopathy: The essentials. 1st ed. Philadelphia: Lippincott Williams \& Wilkins; 2010.

4. Maturi RK, Walker JD, Chambers RB. Diabetic retinopathy for the comprehensive ophthalmologist. 2nd ed. Fort Wayne: Deluma Medical Publishers; 2015. Available from: http://www.drcobook.com/ download.php.

5. American Optometric Association. Diabetic Retinopathy [Internet]. St. Louis (MO); c2018 American Optometric Association. Available from: https://www.aoa.org/patients-and-public/eye-and-visionproblems/glossary-of-eye-and-vision-conditions/diabetic-retinopathy

6. Chan A, Duker JS, Ko TH, Fujimoto JG, Schuman JS. Normal macular thickness measurements in healthy eyes using stratus optical coherence tomography. Arch Ophthalmol. 2006;124(2):193-198.

7. Browning DJ. The relationship between OCT-measured central retinal thickness and visual acuity in diabetic macular edema. Ophthalmology. 2007;114 (3):525-536.

8. Duan XR, Liang YB, Friedman DS, et al. Normal macular thickness measurements using optical coherence tomography in healthy eyes of adult Chinese persons: the Handan Eye Study. Ophthalmology. 2010;117(8):1585-1594.

9. Nagra M, Gilmartin B, Thai NJ, Logan NS. Determination of retinal surface area. J Anat. 2017; doi:10.1111/joa.12641.

10. Caro CG, Pedley TJ, Shrouter RC, Seed WA. The mechanics of the circulation. 2nd ed. Cambridge: Cambridge University Press; 2012. Chapter 13, The systemic microcirculation.

11. Batchelor GK. An introduction to fluid dynamics. 3rd ed. Cambridge: Cambridge University Press; 2000. Chapter 4, Flow of a uniform compressible viscous fluid.

12. da Silva AVB, Gouvea SA, da Silva APB, et al. Changes in retinal microvascular diameter in patients with diabetes. Int J Gen Med. 2015;8:267-273.

13. Tan PE, Balaratnasingam C, Xu J, et al. Quantitative comparison of retinal capillary images derived by speckle variance optical coherence tomography with histology. Invest Ophthalmol Vis Sci. 2015;56(6):3989-3996.

14. Wang Q, Kocaoglu OP, Cense B, et al. Imaging retinal capillaries using ultra- high-resolution optical coherence tomography and adaptive optics. Invest Ophthalmol Vis Sci. 2015;52(9):6292-99.

15. Lombardo M, Parravano M, Serrao S, Ducoli P, Stirpe M, Lombardo, G. Analysis of retinal capillaries in patients with type 1 diabetes and non proliferative diabetic retinopathy using adaptive optics imaging. Retina - J Ret Vit Dis. 2013; 33(8):1630-1639

16. Kundu PK, Cohen IM. Fluid Mechanics. Cambridge, MA: Academic Press; 2007. Chapter 17, Introduction to Biofluid Mechanics.

17. Munson BR, Okiishi TH, Huebsch WW, Rothmayer AP. Fluid Mechanics. 7th ed. Wiley; 2013.

18. Muraoka Y, Tsujikawa A, Kumagai K, et al. Age- and hypertension-dependent changes in retinal vessel diameter and wall thickness: an optical coherence tomography study. Am J Ophthalmol. 2013;156(4):706-714.

19. Rim TH, Choi YS, Kim SS, et al. Retinal vessel structure measurement using spectral-domain optical coherence tomography. Eye. 2016;30(1):111-119.

20. Thornalley PJ, Babaei-Jadidi R, Al Ali H, et al. High prevalence of low plasma thiamine concentration in diabetes linked to a marker of vascular disease. Diabetologia. 2007;50(10):2164-2170.

21. Rabbani N, Alam SS, Riaz S, et al. High-dose thiamine therapy for patients with type 2 diabetes and microalbuminuria: a randomised, double-blind placebo-controlled pilot study. Diabetologia. 2009;52(2):208-212. 
22. Beltramo E, Berrone E, Tarallo S, Porta M. Effects of thiamine and benfotiamine on intracellular glucose metabolism and relevance in the prevention of diabetic complications. Acta Diabetol. 2008;45(3):131-41.

23. BBC NEWS Article. Diabetes Problems 'Vitamin Link' [Internet]; c2018 [Last updated 7 August 2007]. Available from: http://news.bbc.co.uk/2/hi/health/6935482.stm

24. Page, GL, Laight $\mathrm{D}$, Cummings $\mathrm{MH}$. Thiamine deficiency in diabetes mellitus and the impact of thiamine replacement on glucose metabolism and vascular disease. Int J Clin Pract. 2011;65(6):68490.

25. Cinici E, Ahiskali I, Cetin N, et al. Effect of thiamine pyrophosphate on retinopathy induced by hyperglycemia in rats: A biochemical and pathological evaluation. Indian J Ophthalmol. 2016;64(6):434439.

26. Hammes HP, Du X, Edelstein D, et al. Benfotiamine blocks three major pathways of hyperglycemic damage and prevents experimental diabetic retinopathy. Nat Med. 2003;9(3):294-299.

27. Mukherjee C, Wilcox M, Elsherbiny S. Does vitamin D deficiency affect diabetic retinopathy?: A primary care survey and literature review. EC Ophthalmol. 2016;4(1):451-458.

28. Payne JF, Ray R, Watson DG, et al. Vitamin D insufficiency in diabetic retinopathy. Endocr Pract. 2012;18 (2):185-103.

29. Millen AE, Meyers KJ, Liu Z, et al. Association between vitamin D status and age-related macular degeneration by genetic risk. JAMA Ophthalmol. 2015;133 (1):1171-1179.

30. Richer SP, Pizzimenti JJ. The importance of vitamin D in systemic and ocular wellness. J Optom. 2013;6(3):124-133.

31. Elblbesy MA, Hereba AR, Shawki MM. Effects of aspirin on rheological properties of erythrocytes in vitro. Int J Biomed Sci. 2012;8(3):188-193.

32. Vekasi J, Koltai K, Gaal V, Toth A, Juricskay I, Kesmarky G. The effect of aspirin on hemorheological parameters of patients with diabetic retinopathy. Clin Hemorheol Microcirc. 2008;39(1-4):385-389.

33. Do DV, Wang X, Vedula SS, et al. Blood pressure control for diabetic retinopathy. Cochrane Database Syst Rev. 2015;1:CD006127. doi: 10.1002/14651858.CD006127.pub2.

34. Sheps SG. Mayo Clinic Article. Caffeine: How does it affect blood pressure? [Internet]; [Last updated 19 Oct 2017]. Available from: https://www.mayoclinic.org/diseases-conditions/high-blood-pressure/expert-answers/blood-pressure/faq-20058543 